\title{
Alternative Wind Power Modeling Methods Using Chronological and Load Duration Curve Production Cost Models
}

Michael R. Milligan

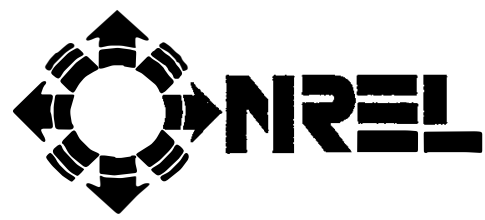

National Renewable Energy Laboratory 1617 Cole Boulevard Golden, Colorado 80401-3393

A national laboratory of the U.S. Department of Energy Managed by Midwest Research Institute for the U.S. Department of Energy under Contract No. DE-AC36-83CH10093 


\section{Alternative Wind Power Modeling Methods Using Chronological and Load Duration Curve Production Cost Models}

Michael R. Milligan

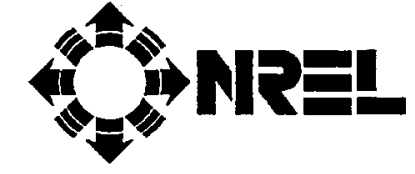

National Renewable Energy Laboratory 1617 Cole Boulevard Golden, Colorado 80401-3393

A national laboratory of the U.S. Department of Energy Managed by Midwest Research Institute for the U.S. Department of Energy under contract No. DE-AC36-83CH10093

Prepared under Task No. WE617010

April 1996 


\section{NOTICE}

This report was prepared as an account of work sponsored by an agency of the United States govemment. Neither the United States govemment nor any agency thereof, nor any of their employees, makes any warranty, express or implied, or assumes any legal liability or responsibility for the accuracy, completeness, or usefulness of any information, apparatus, product, or process disclosed, or represents that its use would not infringe privately owned rights. Reference herein to any specific commercial product, process, or service by trade name, trademark, manufacturer, or otherwise does not necessarily constitute or imply its endorsement, recommendation, or favoring by the United States govemment or any agency thereof. The views and opinions of authors expressed herein do not necessarily state or reflect those of the United States govemment or any agency thereof.

Available to DOE and DOE contractors from:

Office of Scientific and Technical Information (OSTI)

P.O. Box 62

Oak Ridge, TN 37831

Prices available by calling (423) 576-8401

Available to the public from:

National Technical Information Service (NTIS)

U.S. Department of Commerce

5285 Port Royal Road

Springfield, VA 22161

(703) $487-4650$ 


\section{Preface}

As an intermittent resource, capturing the temporal variation in windpower is an important issue in the context of utility production cost modeling. Many of the production cost models use a method that creates a cumulative probability distribution that is outside the time domain. The purpose of this report is to examine two production cost models that represent the two major model types: chronological and load duration curve models. This report is part of the ongoing research undertaken by the Wind Technology Division of the National Renewable Energy Laboratory in utility modeling and wind system integration.

The author would like to gratefully acknowledge the encouragement and support of Jack Cadogan of the U.S. Department of Energy and Al Miller of Problem Solvers International. Francis Chapman at the Environmental Defense Fund, and Chok Pang and Granger Tam at the P+Corporation provided a wealth of modeling assistance. 


\section{Table of Contents}

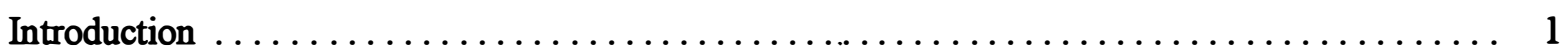

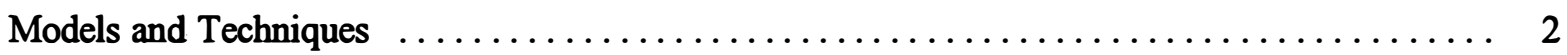

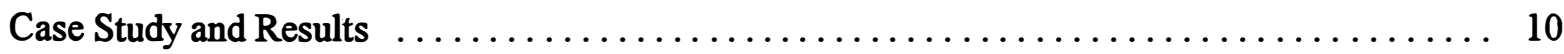

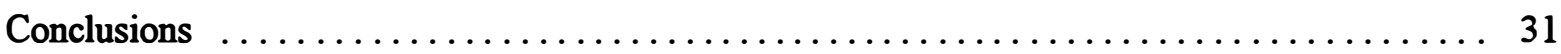

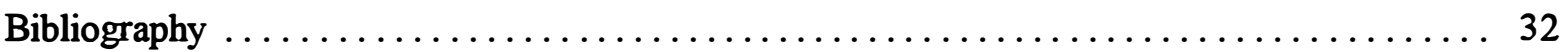

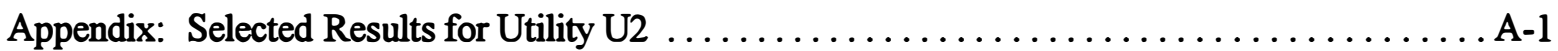

\section{List of Figures}

Figure 1. Cumulative wind power distribution, wind site HP, July $\ldots \ldots \ldots \ldots \ldots$

Figure $2 . \quad$ Utility $\mathrm{Ul}$ generation $\operatorname{mix} \ldots \ldots \ldots \ldots \ldots \ldots \ldots \ldots \ldots \ldots \ldots \ldots \ldots \ldots$

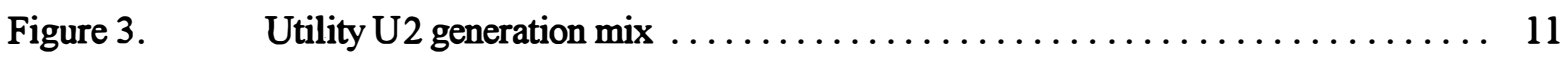

Figure 4. Wind-speed distribution, $\mathrm{HP}$ wind site $\ldots \ldots \ldots \ldots \ldots \ldots \ldots \ldots \ldots \ldots \ldots$

Figure 5. Wind-speed distribution, $\mathrm{WC}$ wind site $\ldots \ldots \ldots \ldots \ldots \ldots \ldots \ldots \ldots \ldots \ldots$

Figure 6. $\quad P+$ peak day simulation for utility $U 1$, no wind $\ldots \ldots \ldots \ldots \ldots \ldots \ldots$

Figure 7. $\quad P+$ peak day simulation for utility $U 1$, High Plains wind $\ldots \ldots \ldots \ldots \ldots$

Figure 8. $\quad P+$ peak day simulation for utility $U 1$, West Coast wind $\ldots \ldots \ldots \ldots \ldots$

Figure 9. $\quad \mathrm{P}+$ average day in peak week, utility $\mathrm{Ul}$, High Plains wind $\ldots \ldots \ldots \ldots$

Figure 10. $\quad \mathrm{P}+$ average day in peak week, utility $\mathrm{Ul}$, West Coast wind $\ldots \ldots \ldots \ldots$

Figure 11. $\quad \mathrm{P}+$ comparison of wind/no-wind cases, changes in energy $\ldots \ldots \ldots \ldots \ldots \ldots$

Figure 12. Utility $\mathrm{Ul}$ gas and oil comparison of peak day $\ldots \ldots \ldots \ldots \ldots \ldots \ldots$

Figure 13. Elfin peak-week subperiods, utility $U 1$, no wind $\ldots \ldots \ldots \ldots \ldots \ldots \ldots \ldots$

Figure 14. Elfin peak-week subperiods, utility U1, High Plains wind $\ldots \ldots \ldots \ldots \ldots$

Figure 15. Elfin peak-week subperiods, utility U1, West Coast wind $\ldots \ldots \ldots \ldots \ldots \ldots$ 
Figure 16. Probability surface for a typical day in January, West Coast wind $\ldots \ldots \ldots 22$

Figure 17. Cost reduction from base case, High Plains wind, utility $U 1 \ldots \ldots \ldots \ldots$

Figure 18. Cost reduction from base case, West Coast wind, utility $U 1 \ldots \ldots \ldots \ldots$

Figure 19. Change in energy from gas and oil units, High Plains wind $\ldots \ldots \ldots \ldots \ldots$

Figure 20. LOLP reduction from base case, High Plains wind, utility $U 1 \ldots \ldots \ldots$

Figure 21. LOLP reduction from base case, West Coast wind, utility $U 1 \ldots \ldots$

Figure 22. Cost reduction from base case, High Plains wind, utility U1, low loads $\ldots \ldots 28$

Figure 23. Cost reduction from base case, West Coast wind, utility U1, low loads . . . . 29

Figure 24. Weekend load, High Plains wind, utility Ul, low loads $\ldots \ldots \ldots \ldots \ldots$ 


\section{Introduction}

Utilities have used production cost and generation expansion models for many years in order to quantify future power production options. Uses for these models range from short-term budgeting to long-range planning. Although the accuracy of the results is important, the complexity of these models sometimes obscures the importance of the input data and the assumptions made by the model. Early models were built on the important work of Baleriaux and Booth, who developed an algorithm that combined hourly loads into a load duration curve (LDC). Under certain assumptions, the load duration curve can be interpreted as a probability distribution. The output of this type of model typically provides expected generation from the various units according to their outage rates and other properties. The appeal of these LDC models was significant because they used less expensive, relatively scarce computer time than chronological models. In fact, many improvements were subsequently made to improve on the LDC models, such as the introduction of partial outage rates and multiple time periods that can be modeled as a separate LDC. The latter improvement overcame one of the chief objections to the "pure" LDC model and allowed modelers to consider peak and off-peak periods separately.

Rau (1980) made an important contribution by introducing the method of cumulants into the probabilistic production-costing framework. This method of approximating the load duration curve as a function of moments led to significant improvements in model execution time. The method of cumulants also has been applied to chronological models, providing this family of models with significant increases in efficiency as well.

As computing power has become less costly during the past several years, chronological models have received more attention. More efficient computing platforms allow analysts to run more detailed simulations, resulting in more accuracy. Proponents of the LDC models argue that, formost long-range planning applications, the LDC model does not result in significant loss of accuracy. In fact, in the out years, uncertainty about fuel prices and technological efficiency will likely swamp any inaccuracies in the algorithm. Proponents of the chronological approach often argue that, although the LDC method may be adequate for long-run simulations, for short-run (e.g., 1-2 years) applications there is less incentive to give up the precision offered by the chronological model.

The choice of model type - chronological or LDC - is particularly relevant when production-cost models are used to examine intermittent renewable resources such as wind power. Many potential effects of specific wind regimes on specific utility systems remain unknown, and production-cost models can help answer some of these questions. For example, if wind power is introduced to the generation mix, which generating unit(s) will be affected and by how much? What is the value of the displaced energy/capacity from conventional units? Will the temporal variation in the wind power be comparable to that in the utility's native load? To properly answer these questions, we must be knowledgeable about the tools that do the measuring and how they treat intermittent resource modeling. The work outlined herein is motivated by the following question: Does the LDC modeling paradigm impose any significant shortcomings in measuring the value of intermittent resources such as wind?

This paper presents case studies of two utilities, each modeled with both an LDC-based model and a chronological model, to illustrate the differences and similarities that result when significant amounts of wind power are modeled on the system. Our intent is to comment on differences between modeling paradigms rather than to judge the specific models.

The paper begins with a discussion of some general modeling issues that apply to intermittent resources such as wind, followed by a more detailed discussion of the model techniques used herein. We conclude with some selected case study results. 


\section{Models and Techniques}

The models discussed herein are Elfin ${ }^{1}$ and $\mathrm{P}+{ }^{2}$ Elfin is a model based on the LDC method. It allows for up to fourteen subperiods and uses a piece-wise representation of the LDC. P+ is a chronological model derived from PowerSym, developed at the Tennessee Valley Authority (TVA). Although the obvious difference between these models lies in the algorithm used, there are several other differences that would result in different model outputs even if the algorithms matched. In the cases reported here, we attempted to minimize these differences by selecting various options when running the models.

\section{The Elfin Model}

The Elfin model uses a representative week to represent each month, although the model can be run in 52-week mode. It can use a full year of load data to calculate the typical-week load duration curves for the representative approach. LDC models build load duration curves by dividing the chronological loads into different time periods. Elfin, for example, divides the loads into months and the months into subperiods. The subperiods can be specified by the user and are usually defined in accordance with the utility's definitions of peak, off-peak, super off-peak, etc. For each of these subperiods, the model first constructs the load duration curve, then performs the unit commitment and economic dispatch modules. Within each of these subperiods, the model assumes that each supply-side resource provides a constant level of capacity (although this capacity level is subject to the forced outage and maintenance outage rates). ${ }^{3}$ Typically, time-varying, supply-side generator schedules are averaged across the subperiod. ${ }^{4}$

Elfin allows for a large number of generator types, including both supply-side and demand-side resources, both firm and nonfirm. There are several types of load modifiers, which can be applied as either demand-side or supply-side resources depending on whether unit commitment and loss calculations are to include the resource. Historically, intermittent generators such as wind have been modeled in this way, because load modifiers are applied to the chronological loads prior to constructing the load duration curve.

Supply-side resources can be designated with either fixed or time-varying generation schedules. If a resource is not a load modifier, its capability is averaged for the time period, accounting for forced and planned (maintenance) outages, unless the plant is modeled with a series of forced-outage rates, as described below. Generators can be subjected to certain constraints, most notably energy constraints for months, seasons, or years. Plants can be designated as "must-run," which means that the plant runs irrespective of its cost, but are otherwise deployed in merit order. Thermal plants can be modeled in up to nine blocks, each with its own heat rate and forced-outage rate. The forced-outage rate (FOR) is an estimate of the probability that the unit will be unable to provide the relevant capacity when it is needed. The block size in megawatts (MW) and the FORs can change

\footnotetext{
${ }^{1}$ Elfin was created by the Environmental Defense Fund.

${ }^{2} \mathrm{P}+$ is a product of the $\mathrm{P}-\mathrm{Plus}$ Corporation.

${ }^{3}$ Elfin Algorithms Guide (1992).

${ }^{4}$ See EPRI/EGEAS guide (1982).
} 
on an hourly basis (and are subsequently combined into the subperiod). Elfin can optimize maintenance scheduling so that sufficient resources are on line to meet the system peak. Elfin does allow for externalities and maintenance to be considered as part of cost if desired, and contains an option to dispatch, subject to minimum emissions.

The user can set the commitment target to be either some combination of a percentage of system load and adder to the period peak load. This target contains the utility native load, losses, and any operating reserve requirement. Commitment refers to the level of spinning and quick-start capacity that is available. Slow-start units, once committed, can be dispatched to meet load. The user also can set the spinning target, which is the constraint observed for the reserve requirement during the period. The spinning target can only be met with plants that are on line and synchronized, whereas the commitment target can be met with off-line, quick-start units in addition to plants that are on line.

Elfin calculates loss-of-load probability (LOLP) using a 201-point piecewise linear approximation to the LDC. LOLP can be calculated for any time period or for the entire year. The model provides an operating LOLP; offline, uncommitted units are not considered in the LOLP calculations. Elfin has an option that allows the user to calculate hourly LOLP using all installed capacity, with various options for including hydro, pumped storage, and other dispatchable reserves. These options are useful for performing reliability studies.

\section{The P+ Model}

The $\mathrm{P}+$ model actually contains several separate programs. The programs P-Month and P-Week are the chronological production-costing programs and can produce output for the hour, day, month, and year. These programs use the same algorithm but different time scales. There is a separate module that is the reliability tool; this was not analyzed here. However, the production-cost modules do produce an estimate of loss-of-load hours for various time periods using the method of cumulants. This method uses a function of the moments of the probability distribution of the load rather than a piecewise representation of the effective load curve.

Generator types allowed by $\mathrm{P}+$ include thermal units, combustion turbines, hydro, energy storage, and transactions/interchanges. Commitment and dispatch occur in sequence by type, beginning with transactions, observing fixed energy constraints, and dispatching in merit order. Previously committed units are used, and minimum uptime and downtime constraints are enforced. The default mode of operation is probabilistic, similar to that of the Elfin model. The probabilistic option convolves each unit with respect to its forced-outage rate. The $\mathrm{P}+$ model also contains a Monte Carlo option that makes random draws representing the outage state of each unit. This approach is computationally much more intensive, but is useful in estimating the mean and variance of the model outputs. A third option called "branching" allows the user to specify a generator as the branching node. Each outage state of the branching node is simulated, followed by convolution of the other units with the probabilistic simulation algorithm. This method allows the user to focus on outage effects of particular units while retaining the probabilistic approach for the other units. The "branching" method represents a more computationally efficient method than Monte Carlo, but is generally less accurate; however, it is (in the limit) more accurate than the strict probabilistic approach.

Transactions can be specified on the basis of user-defined subperiods. These subperiods are typically defined with respect to the utility's definition of peak, off-peak, and super-off-peak. The $\mathrm{P}+$ model provides a variety of options for shaping a transaction with respect to peaks and valleys. Load modifications for demand-side management (DSM) or intermittent resources can be modeled as transactions. 
Thermal units are modeled using capacity, heat rate, fuel price, and availability data. A separate module can optimize maintenance scheduling by levelizing the reserve margin. Thermal units can be modeled as multiblock units, with 4-5 blocks as a typical maximum. ${ }^{5}$ Probability levels are fixed through time, but the block ratings can change hourly. The $\mathrm{P}+$ model explicitly considers unit ramp rates, providing for a more realistic picture of generator operation. One major strength of $\mathrm{P}+$ is its fuel logic, which considers constraints on fuel delivery and storage.

\section{Methods for Modeling Wind Power}

On an a priori basis, it is reasonable to assert the superiority of the chronological approach over the LDC approach for modeling wind power. However, it is not intuitively clear what the extent of the differences might be between these methods. Furthermore, many other factors influence a model's output. For example, in earlier work (Milligan and Miller 1993) we demonstrated a range of outputs from the same model that resulted from different methods of wind power modeling and wind data sampling. If such differences could be obtained using a single model, what are the implications if more than one model is used? A larger question is, which model is closest to reality? Due to the partial predictability of wind, model backcasting must take the predicted level of wind power into account when looking backward in order to recognize the accuracy of hindsight over that of foresight. ${ }^{6}$ It is clear that there is no widespread agreement on model accuracy because many production-cost and generation-expansion models that use different calculation methods thrive in the marketplace.

Given the range of outputs described in an earlier paper (Milligan and Miller 1993), one goal here is to begin looking at whether generalizations could be made with respect to the various LDC model results compared to chronological model results. However, there are several situations in which chronology may be important, the most significant of which may be differences in unit commitment. Committed units in the LDC model framework are constrained because, once committed, they cannot be decommitted until the following period (typically 1 week). Chronological models can decommit a unit if it is not needed, subject only to the minimum up-time and down-time constraints of that unit.

It is also possible that extreme short-term variation in wind power output could cause excess cycling, as units are required to support periods of low wind power output. During periods of high wind power output, these units would not be needed. If pushed to the limit, the unit cycling could conceivably become constrained by unitramping constraints. If this were to occur, excess capacity would probably be required during periods of low wind output because unit-ramping constraints would not allow the reduction of conventional output quickly enough to compensate for the increase in wind power output. These periods of excess capacity would result in a reduction in the potential benefit of wind power plants.

It is not clear, however, that such large-scale chronological variation in wind power exists. ${ }^{7}$ Figure 1 is taken from the High Plains (HP) wind site described in our earlier work and used here. The graph shows the output of

\footnotetext{
${ }^{5}$ The number of blocks can be customized to the user.

${ }^{6}$ See Milligan, Miller, and Chapman (1995) for a discussion of wind-forecasting benefits to a utility.

${ }^{7}$ This is primarily due to a lack of publicly available data.
} 


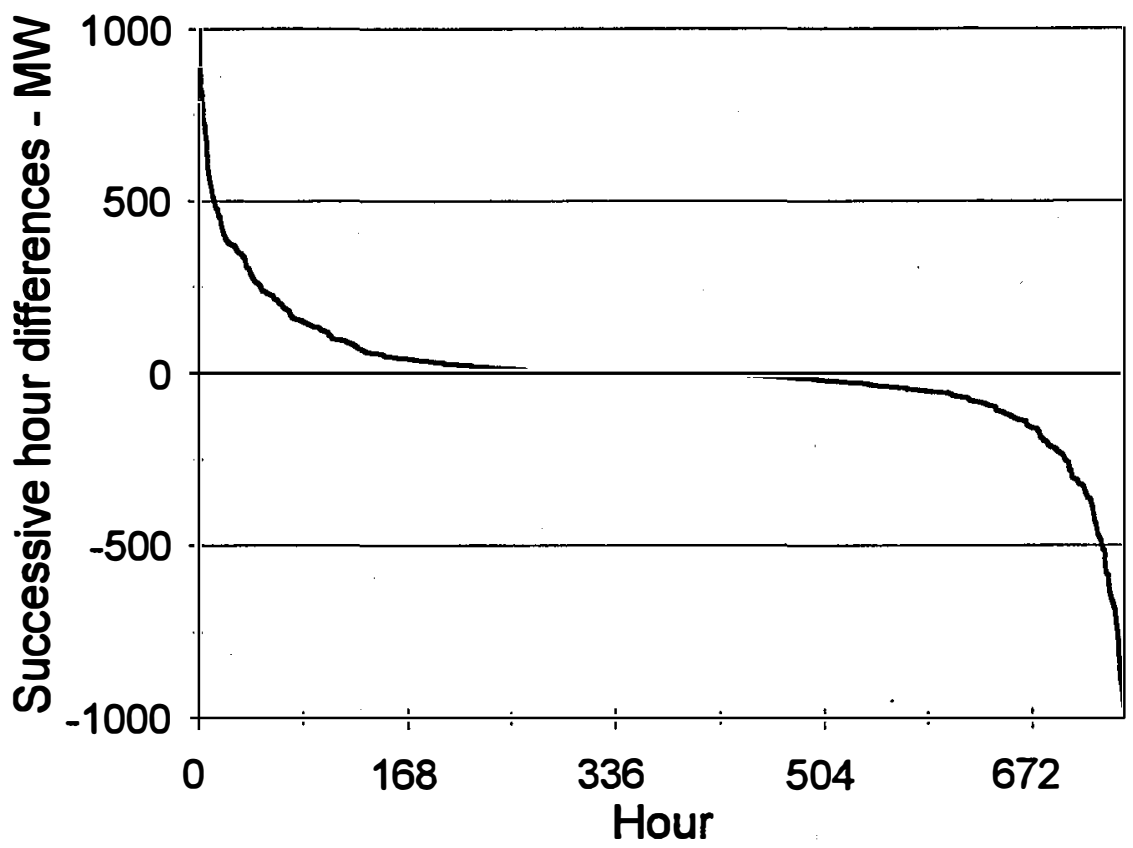

Figure 1. Cumulative wind power distribution, wind site HP, July

a hypothetical wind plant of approximately $1,000 \mathrm{MW}$ and is based on actual wind data. ${ }^{8}$ Hourly power outputwas calculated first, followed by the first difference of power between successive hours. The resulting data were then sorted and graphed. The curve is, somewhat surprisingly, symmetric. Reading the vertical axis at 500 MW, we see that wind power output increased by $500 \mathrm{MW}$ or more approximately 15 times during the month. Taking both tails of the distribution, we see that wind power increased or decreased by $25 \%$ or more of its capacity within an hour's time about 80 times (11\%) in a month.

This indicates that large swings in wind power are possible, but they do not occur with high frequency given this small sample. Much more analysis and data are certainly required to draw more general conclusions. While these preliminary results justify a utility's interest in precise estimates of the effect of ramping on its load-following units, they suggest that the problem may not be severe and warrants further examination.

Many production-cost and generation-expansion models exist. This discussion is intended to apply to both the LDC and chronological families of models, but the focus is on Elfin and P+. For an excellent discussion of chronological-model capabilities, refer to Marnay and Strauss (1989).

Most production-cost models offer two broad methods of modeling intermittent resources such as wind. The first method is to treat the wind power as a load modification. The hourly wind power production is subtracted from the system load before the commitment and economic dispatch are calculated. The clear advantage of this approach with LDC-based models is that it retains all of the chronological detail available. This is especially important during peak hours when a majority of the system LOLP occurs and dispatch errors are generally not tolerable.

${ }^{8}$ Sandusky et al. (1983). 
A disadvantage of the load-modification method is that it assumes the wind power output will be achieved with certainty, and there is no explicit accounting for the probability of higher or lower output. However, it is not clear whether the resulting LOLP is too high or too low. A full year of actual hourly wind data can be viewed as a particular realization of a stochastic series. As such, we can describe a probability distribution that characterizes the random wind-speed variable in each hour. The shape of the distribution is not important for the purposes of this discussion. For each hour of the year, the actual wind speed can be viewed as the result of taking a random draw from the probability distribution. For each of these draws, the distribution specifies probabilities associated with each possible wind speed and we will generally have non-zero probabilities associated with drawing values either above or below the mean value. For each of the hourly wind-speed values in the actual data set, we therefore do not know if the value is above or below the mean unless we have explicit knowledge of the underlying probability distribution. Therefore, we do not know whether the LOLP for the hour is higher or lower than the LOLP value based on the mean wind speed for the hour. If the wind-speed distribution for each hour is symmetric, then the expected value of the number of draws less than the mean is the same as the expected value of the number of draws greater than the mean. However, since LOLP depends so heavily on the peak period, different realizations of the time series will likely cause significant variations in the system LOLP. A clear implication is that the load-modification method should be treated with extreme suspicion when performing reliability studies of wind plants, unless some form of repeated wind-data sampling and multiple production model runs are executed.

The second method is modeling the intermittent plant as a supply-side unit. Here wind is dispatched in merit order and convolved into the LOLP calculation with the conventional units. Because wind plants have no fuel cost and a very small variable operation and maintenance (O\&M) cost (i.e., O\&M cost that is a function of kilowatt-hour production, which may or may not be included in the dispatch decision), they will invariably be dispatched first, and all available wind power will be used. The result is that the generators operating on the margin (i.e., the load-following units) will have a reduced output level. The clear advantage to this approach is that the wind plant is convolved into the reliability calculation. There is also the intellectual appeal that wind power is treated in much the same way as the conventional supply-side units in the commitment/dispatch process, rather than as a load modifier.

The inability of the load-modification method to correctly account for the probability that wind power is unavailable increases the appeal of supply-side representations of wind power, in which forced-outage rates can be used to describe the availability of wind power. The supply-side approach has several variations. The first is to provide the model with a value for expected wind power for the month, for example, along with a forcedoutage rate that is based on long-term wind availability during that period. If long-term data are not available, as much data as possible should be used. The interpretation of this approach is that we are providing the production-cost model with an expected level of wind power for the period, along with a measure of the variance. Caution must be used in providing the appropriate mean wind level, depending on the technique used by the LDC model to calculate the available capacity of the unit, given the forced-outage rate. Clearly, however, this approach is not adequate for calculating the short-term (hourly) effects of wind power on the conventional generation system, because the detail data is lost. Also, this simplistic supply-side method makes it difficult to properly account for the stochastic property of the wind resource. For these reasons, this simplistic form of the supply method of modeling wind power is the most difficult to justify of all the methods presented in this study.

A second variation of the supply-side approach is to allow for time-varying forced-outage rates. This method is called the "probabilistic supply-side" method, and can be viewed as providing a time-dependent probability distribution that represents the availability of wind power. It is described in Milligan and Miller (1993). It has the advantage of providing both a time-varying component and a probabilistic component to the wind power 
calculation. Greater accuracy can be achieved when a model allows for higher levels of temporal disaggregation and for more precise specification of the probability distributions.

Unfortunately, it is not possible to predict the relative performance of the two supply-side modeling variations, either with respect to each other or with respect to the load-modifier approach. The supply-side methods can result in either higher or lower LOLP calculations, depending on the characteristics of the system that is modeled. This difficulty can be seen in a simple example. Suppose that the modeler has chosen a subperiod consisting of only 2 hours, for example, 3:00 and 4:00. System loads are 1,200 MW and 1,300 MW, respectively, for these 2 hours. Suppose that wind plant output is $100 \mathrm{MW}$ at 3:00 and $200 \mathrm{MW}$ at 4:00. Using the load modification approach, the wind contribution on-peak is $200 \mathrm{MW}$, reducing the remaining load to $1,100 \mathrm{MW}$. Using a simplistic supply-side characterization of the wind plant will give a different answer for this remaining load. Averaging the wind generation across the subperiod gives us $150 \mathrm{MW}$ for each hour. Conventional generation must therefore supply approximately $1,150 \mathrm{MW}$ on-peak and 1,050 off-peak. Assuming the same conventional generator availability between these two cases, the LOLP of the load-modification case will be lower than that for the supply-side case because the remaining equivalent load is less. Furthermore, there is no forced outage associated with the wind plant when it is modeled with the load-modification approach, further biasing the LOLP downward.

Now suppose that the chronology of the wind availability in this example is reversed, so that $200 \mathrm{MW}$ is available off-peak and $100 \mathrm{MW}$ is available on-peak. With the load modification approach, we calculate $1,000 \mathrm{MW}$ and $1,200 \mathrm{MW}$ required generation by the conventional units. Contribution of wind on-peak is $1.00 \mathrm{MW}$. The calculation of the average wind power for the subperiod is unchanged from the earlier case at $150 \mathrm{MW}$, with the remaining generation providing $1,150 \mathrm{MW}$. In this scenario, the load-modification case will likely cause a higher LOLP calculation because the remaining generators must provide more output during the system peak than would be necessary with the supply-side case. This differs from the first example, in which the load-modification case resulted in a lower LOLP calculation. Clearly, the relative performance of the supply-side and load-modification methods depends on the chronological relationship between loads and wind power and cannot be consistently ranked.

Using a multiblock probabilistic characterization of the wind plant further complicates the problem. The available capacity of the wind plant is calculated as the expected value, given the various forced-outage rates for the hours in the subperiod. As in the simplistic supply-side case, the model uses only this one capacity value for the wind plant during the subperiod. The shape of the probability distribution of wind power availability will determine whether a higher or lower LOLP will be calculated. If there is a high probability of achieving rated output during the period, then expected output will be higher, with a corresponding decrease in LOLP. Conversely, if the probabilities favor a lower level of output, LOLP will increase because the conventional units must supply a higher portion of the load. ${ }^{9}$ If the forced-outage distribution is accurately represented in the model, the expected capacity of the wind plant will likely be a reasonably good estimate of its capacity value. However, a caveat is that model output may report the wind plant at full capacity at a high forced-outage rate, even though there is a low probability that the wind plant will actually reach full capacity. Though this is technically correct, this value should not be used to determine capacity value of the wind plant because it will positively bias the result.

\footnotetext{
${ }^{9}$ This assumes that the annual capacity factor of the wind plant is less than the effective capacity factor of the unit that is displaced by wind, after accounting for maintenance and forced outages.
} 
These two modeling methods - load modification and supply side - also are available with chronological models. For example, $\mathrm{P}+$ allows time-varying capacity to be modeled as a transaction, which results in the subtraction of wind power from the system load. After all transactions have been processed, the conventional units' commitment and dispatch are calculated. This approach is subject to the same criticism as with the LDC model - the conventional hydro-thermal system need only meet the modified load net of wind. The result is a higher calculated level of reliability than actually exists.

Alternatively, the wind resource can be modeled as a supply-side unit with chronological models. If the model supports time-varying forced-outage rates, then we can specify both the time variation and probabilistic nature of the wind resource. Although $\mathrm{P}+$ does not allow for variation in the probability values, it does allow the thermal output level to change, given a fixed set of probabilities. Using this method, five points on a probability distribution curve are selected and the horizontal axis scale is allowed to change hourly, so the expected value of the wind power can be specified as a function of time. An advantage of the underlying chronological structure of the model is that hourly expected wind capacity is calculated and folded into the hourly calculation of the conventional units. At present, the Wind Power Simulator (WIPS) pre-processor model used in this work does not have the capability of calculating the inverse of the large number of probability distributions that would be required by the time-varying approach used by $\mathrm{P}+$, so we were unable to test this approach.

\section{Commitment and Economic Dispatch}

The unit commitment methods used by these two models may seem similar on the surface, but differences due to the chronology of the respective models can cause significantly different commitment effects, especially during off-peak periods. The Elfin model asks the user to specify a commitment target, which can be any combination of percentage of load or adder to load. Weekend commitment targets can be specified separately, and the commitment algorithm proceeds accordingly. The commitment order is based on the expected average variable cost of each plant at its most efficient operating level. This average cost can, at the modeler's option, include variable O\&M costs and emission penalties. The committed capacity is reduced by the forced-outage rate, resulting in an expected capacity level for the plant. Elfin performs its unit commitment routine once during the week and once on the weekend. The unit commitment is based on the peak subperiod, and commitment levels are not changed during the week. Weekend commitment is based on the weekend peak, and does not change during the weekend. Because quick-start units count toward the commitment target, they are available without necessarily being dispatched. If the utility has sufficient quick-start units, it is possible that the slow-start units can be ramped down so that no excess capacity exists during minimum load conditions. If a utility depends heavily on slow-start units without much quick-start capability, then during minimum load periods the Elfin model may not be able to reduce spinning capacity enough to avoid spillage. In this case, a significant level of wind power during minimum load could be useless to the utility. The utilities modeled herein did have sufficient quick-start capacity, so there was no spillage.

A somewhat peculiar anomaly in commitment can occur with LDC models under certain unusual conditions. Because commitment is based solely on the peak period, a significant reduction in available resources during an off-peak period can cause a commitment deficiency off-peak, even though the commitment target was met during the peak period. For example, if a firm contract with a neighboring utility provides for capacity during the system peak, and if that capacity is only available for the peak, then off-peak commitment may not be sufficient to cover the target. To solve this problem, additional capacity would need to be committed during the peak, which would result in excess committed capacity on-peak in order for the off-peak target to be met. 
Elfin's economic dispatch routine maintains consistency between chronologically adjacent subperiods by simultaneously dispatching across the subperiods. Chronology is only observed at the subperiod level, keeping the model from making illogical dispatch decisions such as dispatching a slow-start plant in the morning and afternoon but not during midday. Dispatch order proceeds in merit order, subject to must-run constraints. Upper blocks of slow-start thermal plants are counted toward spinning reserve if those units are committed; they are dispatched in economic order along with other units and blocks in the system. Elfin can also dispatch units that are priced at marginal cost.

The $\mathrm{P}+$ commitment logic for thermal and pumped storage units is conceptually simpler because the model proceeds chronologically. Fixed-energy transactions are dispatched first, followed by hydro and limited energy resources, and finally thermal and pumped storage systems. Slow-start units are committed and dispatched in accordance with their ramp rates. Once a unit is committed, it is subject to minimum uptime and downtime constraints, which can be enforced directly in the chronological framework. The accuracy of the commitment process is quite good, because the target is a function of chronological load. After commitment and dispatch have been calculated, the model checks to make sure that no contract fuel violations have occurred. Should a violation occur, $\mathrm{P}+$ adjusts its commitment schedule within the fuel delivery and storage constraints specified by the user.

The P+ model's use of cumulants is likely to reduce the accuracy of the calculations near the tail of the LOLP distribution. This effect is probably insignificant during most of the convolution cycle, but is a possible contributor to inaccuracies in the LOLP or loss-of-load hours (LOLH) calculation. ${ }^{10}$

It is worth noting that at the time of this writing, the utility industry is facing extraordinary changes. Several states, including California and Massachusetts, are moving toward a deregulation of the utility industry. What will emerge from this effort is unclear at the present time. However, the new industry structure must preserve certain attributes in order to remain viable. The existence of a largely deregulated generation market and customer choice (to some unknown degree) of service providers is stipulated. One primary goal of restructuring the industry is to create a market that provides incentives for the efficient generation and distribution of electricity. To that end, some form of market coordination must occur. This coordination may take several forms with differing degrees of success. However, if the electricity market is to function efficiently, then the process of economic commitment and dispatch, in some form, must somehow be elicited by the market. What is not clear now is whether this coordination can be brought about by the "pure" market via bidding to a pool or network operator or by some other scenario. It appears likely that some entity will be running production-cost models, albeit with different parameters and in a different industry structure, but power-production-cost questions will still need to be answered.

${ }^{10}$ Mamay and Strauss (1989). 


\section{Case Study and Results}

To begin assessing the differences one might ind when modeling wind power with LDC and chronological models, we set up a series of cases using two utilities and two wind regimes, assuming utility ownership of the wind plant. We calibrated the model inputs so that the results from the models matched as closely as possible, then ran various wind generation cases with each model.

To calibrate the two models, several factors had to be considered in light of the differences in modeling style and input requirements. To hold the inputs constant between the models so that we could concentrate on algorithm differences, we used one representative week of load data per month in both models. Although this would not be an approach used by practitioners of chronological modeling, allowing the two models to utilize different descriptions of system load would have introduced another source of variation.

Certain power purchase and exchange contracts were simplified in both model data sets to facilitate comparison between intermodel and intramodel runs. In the P+data set, we did not specify ramp rates for the slow-start generation units. Although including these rates would have provided greater accuracy, leaving them out eliminated another source of variation between model results.

We provided both Elfin and $\mathrm{P}+$ with 8,760 hours of wind generation for the year. Elfin performs a subperiodaveraging routine so that each month's data are averaged into a typical week; the chronological model $\mathrm{P}+$ dispatches each typical week four times, using a full month of wind generation. We can interpret these time-scale differences as follows: Elfin calculates average wind power, dispatches one typical week per month, and then scales the weekly values to the monthly values. P+ dispatches the typical week four times with the actual wind generation, which normally varies from week to week. Ignoring all other differences between the models, any variation in the outcomes of the models is due to the constraints imposed by the LDC simplification, to the extent that they exist.

Each of the utilities in this study possesses units with a range of generator fuels, fixed transactions with other utilities, and qualifying facilities (QFs) - power purchases that qualify under the Public Utility Regulatory Policies Act (PURPA), and are priced at the utility's avoided cost. The various resources consist of hydro, coal, nuclear, natural gas, oil, combustion turbines, and pumped storage. Each system was modeled with its existing transmission constraints, but we did not explicitly consider the effect of wind generation on the existing transmission system. The resource mixes for the two utilities are shown in Figures 2 and 3, respectively.

We explored several methods of modeling wind power in the two utility systems. Using each method, we compared a base case with no wind power to cases with wind power simulated from two distinct wind regimes. The data for these hypothetical wind plants are based on actual wind data collected as part of the U.S. Department of Energy Candidate Site program (Sandusky et. al. 1983) and processed with the WIPS preprocessor model. The first wind site is a High Plains location (referred to as HP hereafter), and the second is located on a West Coast (WC) mountain pass. Power output was calculated on an hourly basis, accounting for electrical losses, wake effects, and mechanical availability. Curves showing the fit between the actual data distribution and two probability distributions, the Rayleigh and the Weibull, are shown in Figures 4 and 5. 


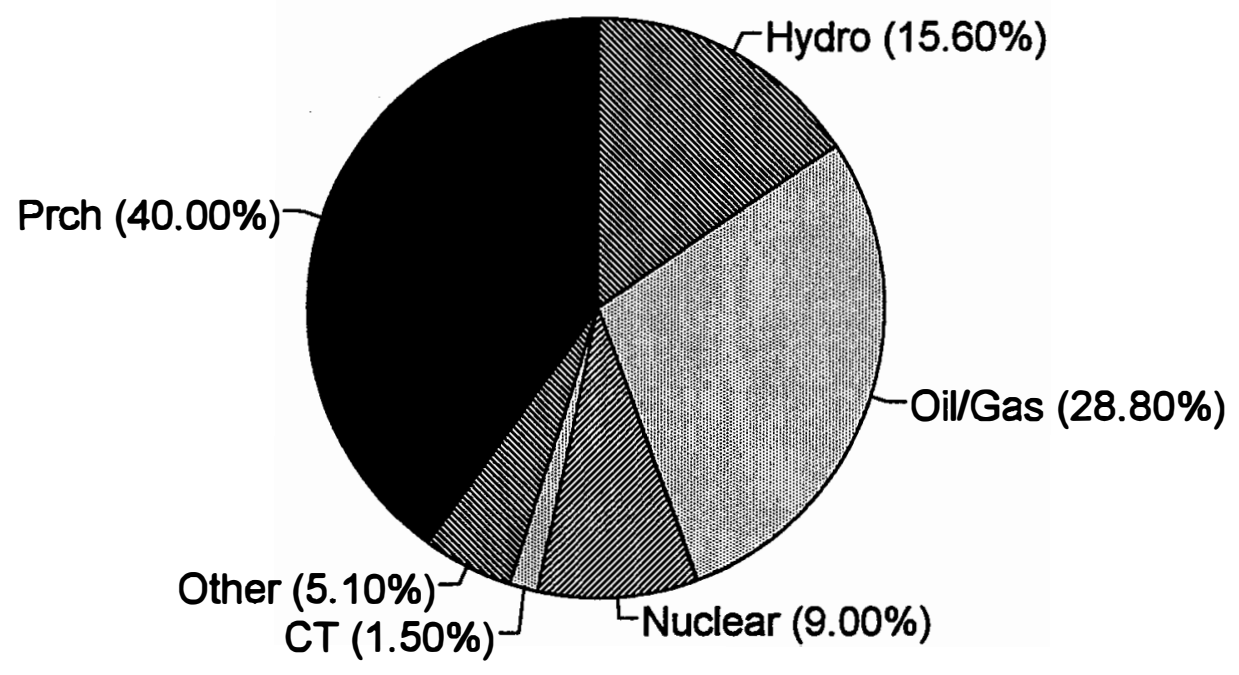

Figure 2. Utility U1 generation mix

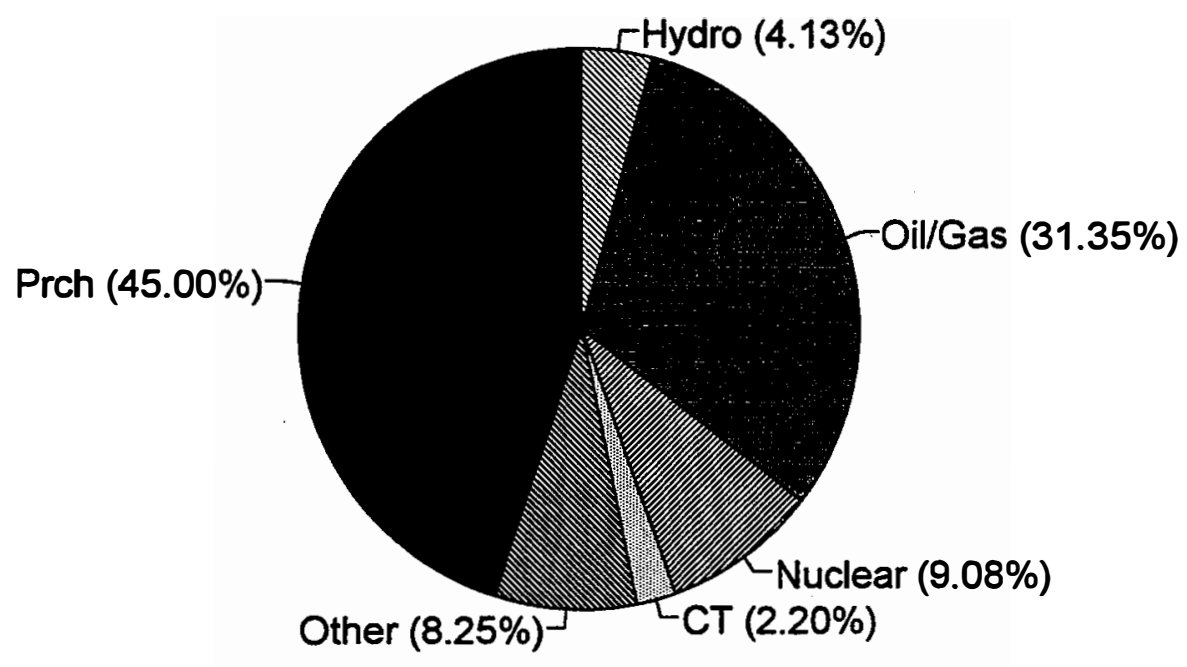

Figure 3. Utility U2 generation mix 


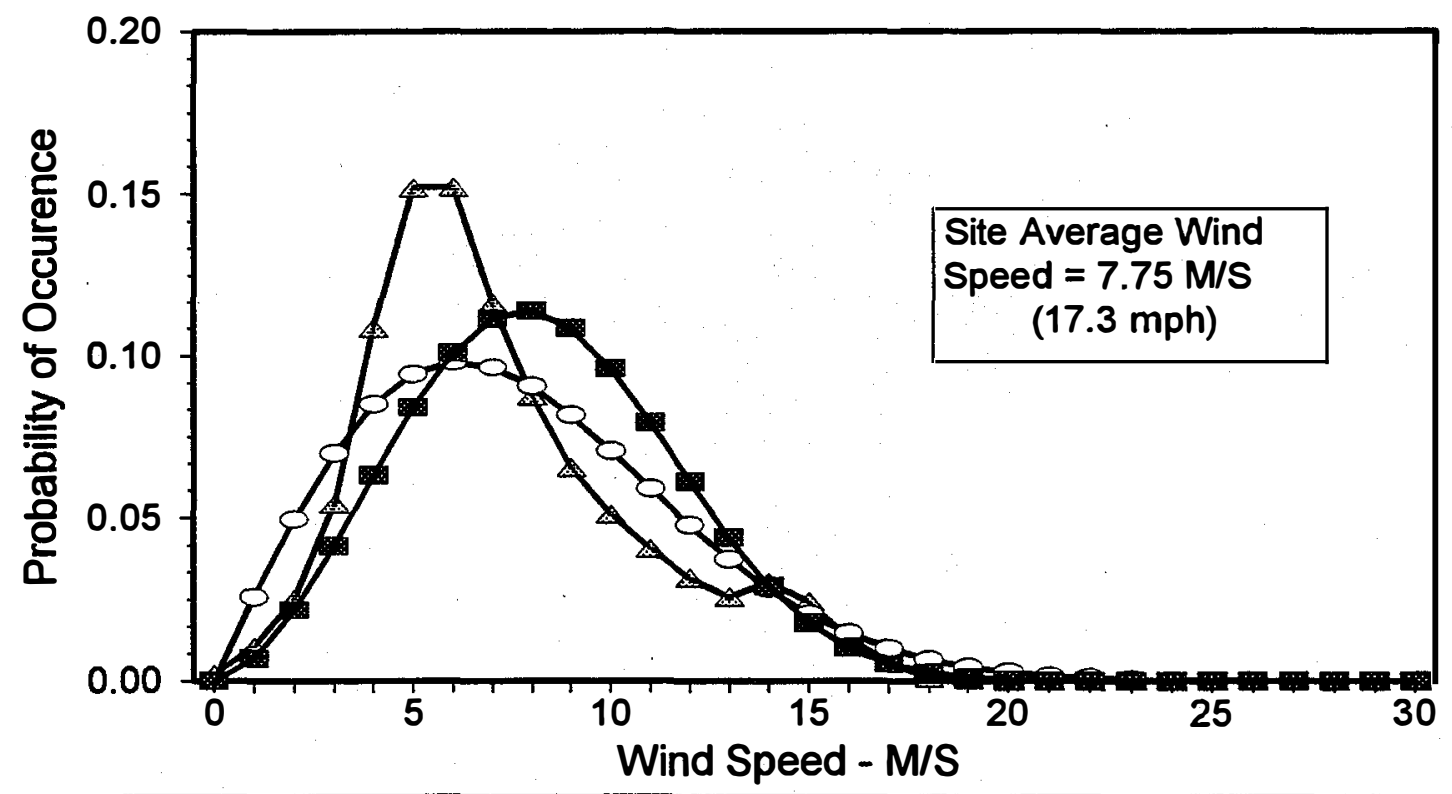

Actual Wind Speed $\rightarrow$ Rayleigh Distribution $\rightarrow$ Weibull Distribution

Figure 4. Wind speed distribution, HP wind site

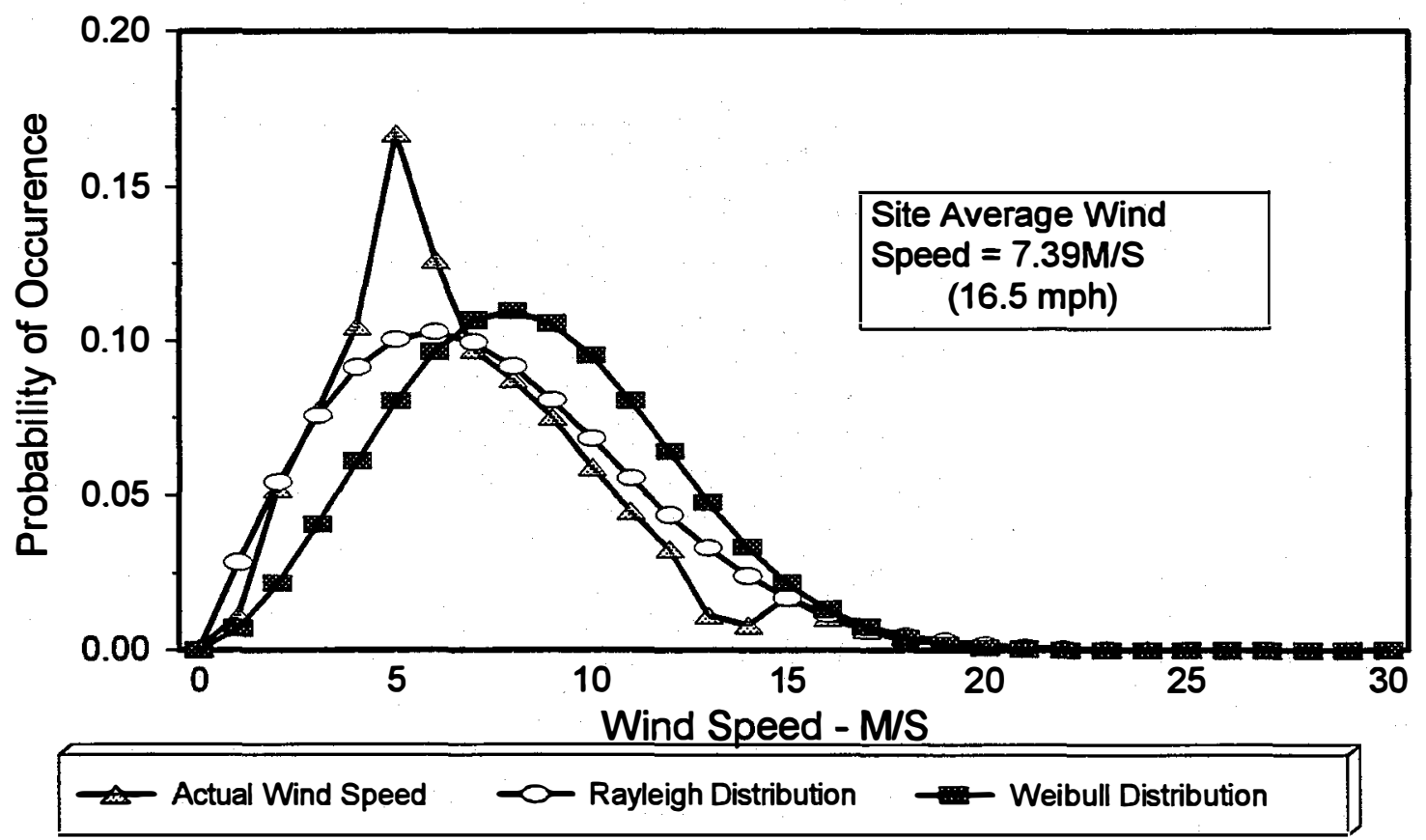

Figure 5. Wind speed distribution, WC wind site 
This paper includes results from two different sets of utility load data: a "high-load" case and a "low-load" case. The former provides us with a look at the two utilities when capacity is in short supply and peak commitment targets cannot always be met. The "low-load" case allows us to examine some off-peak results for utilities that can meet the commitment target.

\section{P+ Peak Day Results}

We begin with some of the $\mathrm{P}+$-model results for the system peak day using the high-load scenario. Off-peak and annual results are discussed below. Figure 6 shows the hourly generation by unit type for the no-wind case for utility Ul. For clarity, purchases have been taken out of the graph. The generation is plotted in (approximately) dispatch order, from the bottom up. On the bottom we see the base load nuclear units, whose output is constant throughout the day. The "other" category includes a mix of other base load units, that also remain constant for each hour. The next level up contains the gas/oil units, which clearly make a large contribution to the daily load swing, as do the hydro plants in the next level. At the very top we see the small contribution of the combustion turbines, which operate for approximately 6 hours during the system peak.

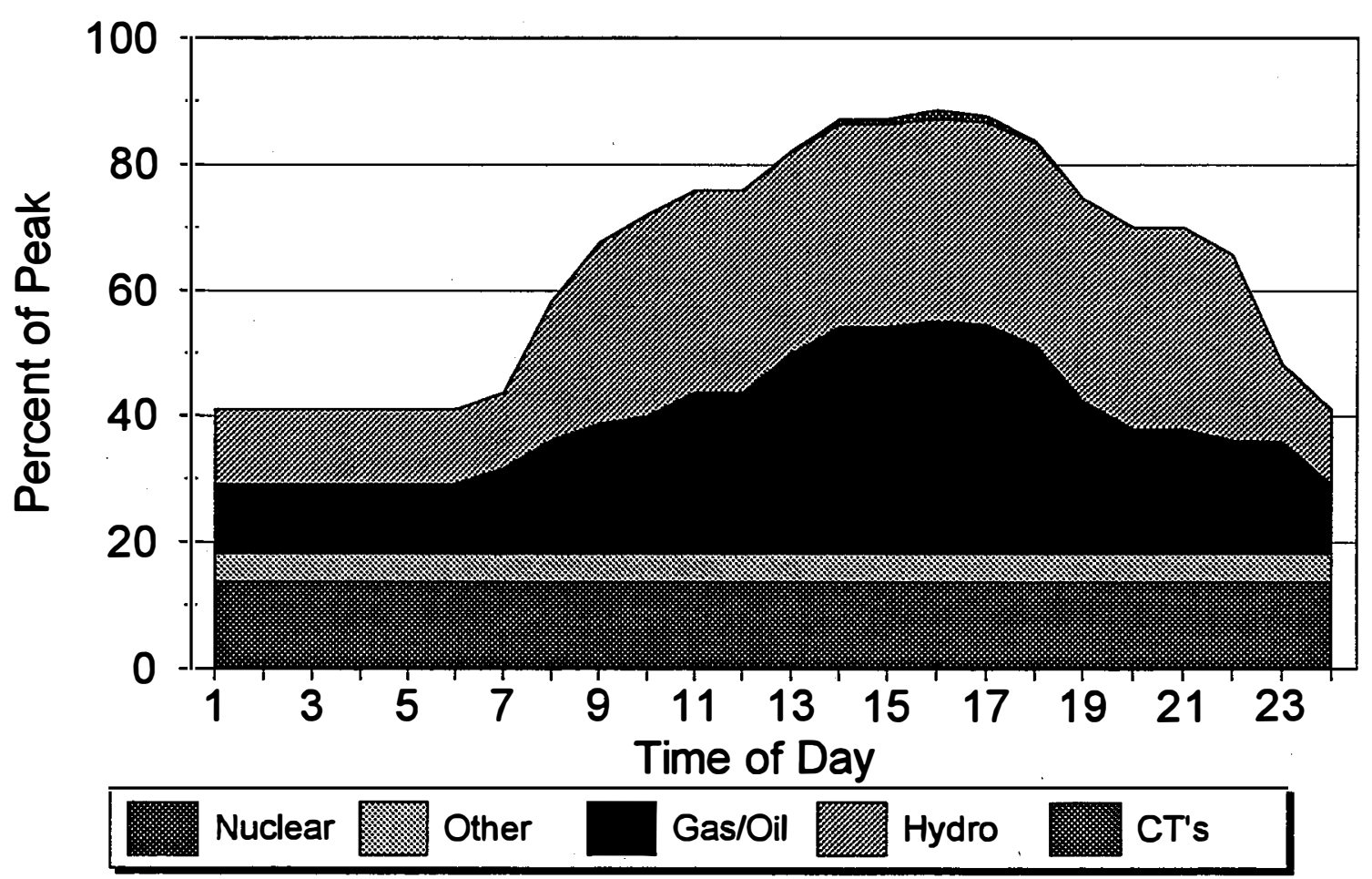

Figure 6. $P+$ peak day simulation for utility U1, no wind 
The wind penetration in each system is modeled to be approximately $4 \%$ of system peak load (at rated capacity). Figure 7 shows the peak day effect of adding the HP wind plant to the generation mix. If modeled as a supplyside resource, wind would be "dispatched" first and would likely be graphed below all other resources. As modeled here, wind is treated as a firm transaction and therefore subtracted from system load prior to unit commitment and dispatch. The wind plant is graphed immediately above the base load generation in each of the following figures to help clarify the constant base load output with and without wind.

Figure 7 should dispel the notion that wind somehow offsets the generation of baseload units. To calculate the effect of adding wind generation (or any other type of generation) to the system, the commitment and dispatch simulations are run with and without the new generators. Although direct comparison between Figures 6 and 7 is difficult, it is clear that the units most affected by the introduction of wind are the intermediate and peaking units, not the baseload units. The numerical simulation results accurately show that the output of all baseload units is virtually unchanged by the introduction of wind power.

It is worthwhile to pursue the economic justification that base load generation is generally not affected by the addition of intermittent resources into the system (unless a base load unit is on the margin during low-load periods). Suppose that, for simplicity, we have a utility with two generation sources: a 100-MW base load coal plant and a 50-MW natural gas unit. The variable-dispatch costs of these units are 40 and $50 \mathrm{mills} / \mathrm{kWh}$, respectively. System load including reserve requirements for the hour is $120 \mathrm{MW}$. For simplicity, ramping constraints are ignored in this example. To minimize cost for the hour, the optimal dispatch strategy will schedule
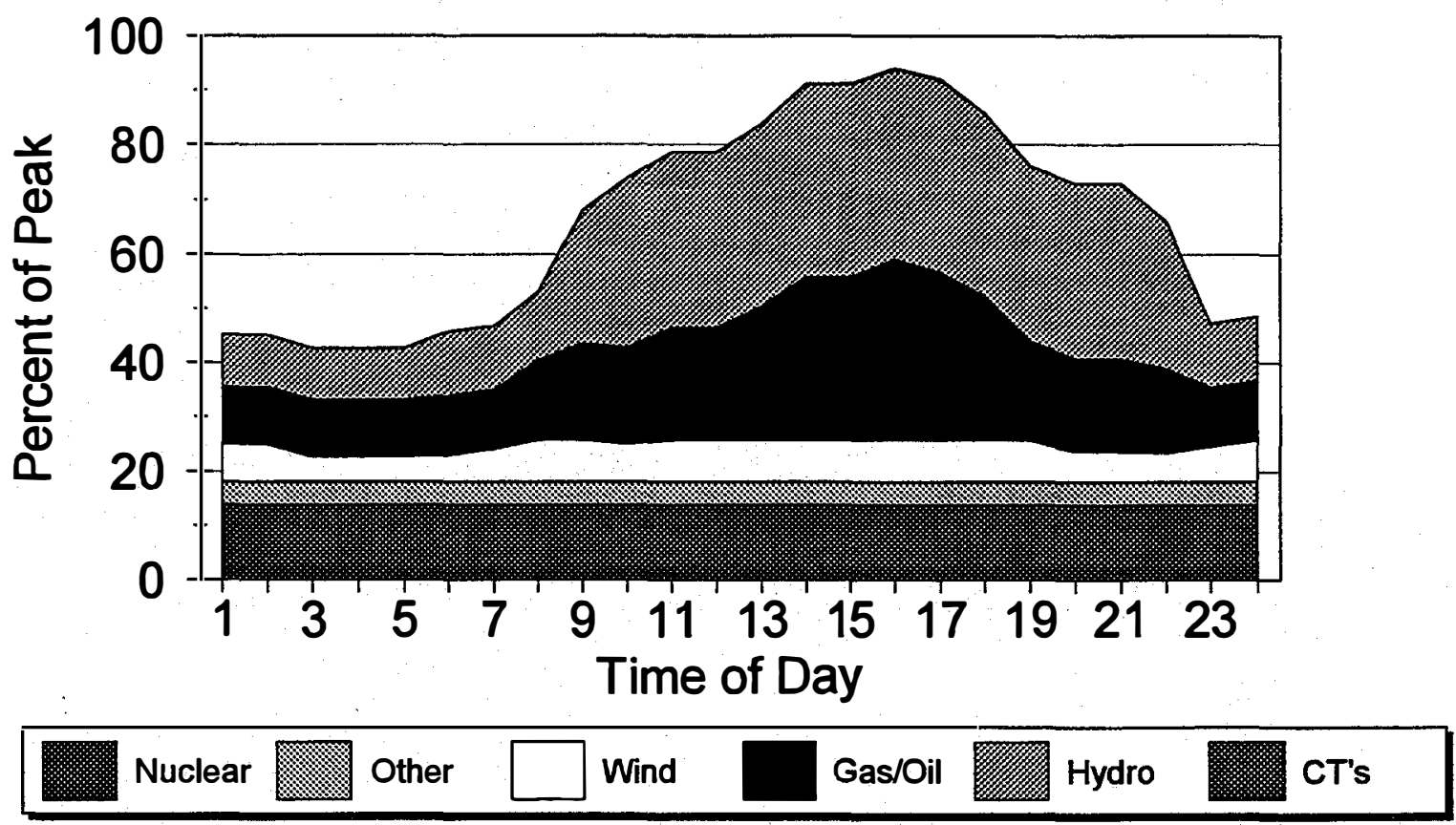

Figure 7. P+ peak day simulation for utility U1, High Plains wind 
the coal plant at full load, $100 \mathrm{MW}$, and the natural gas plant as the load-following unit. Costs for the hour can be calculated as $\$ 4,000+\$ 1,000=\$ 5,000$. If we introduce $10 \mathrm{MW}$ of wind generation for the hour at zero dispatch cost, the obligation for the hour is still $120 \mathrm{MW}$. Subtracting the $10 \mathrm{MW}$ of wind from system load, the thermal system needs to generate $110 \mathrm{MW}$. The least expensive way to do this is to run the base load unit at full capacity, $100 \mathrm{MW}$, and reduce the load on the gas unit. Total cost for the hour is now $\$ 4,000+\$ 500=$ $\$ 4,500$. Suppose that, instead, the utility chose to reduce base load output from $100 \mathrm{MW}$ to $90 \mathrm{MW}$, holding the gas unit at $20 \mathrm{MW}$. Total cost for the hour is then $\$ 3,600+\$ 1,000=\$ 4,600$, which is clearly not a minimum-cost solution to the dispatch problem. Wind plants do not generally cause changes in base load generation, only in units on the margin (load-following units). In the absence of other constraints, such as voltage support, and tie-line support, the rational behavior of the dispatcher is to reduce output from the most expensive unit that is on line, not to reduce output from the least expensive unit.

Although the output of baseload units is generally unchanged as a result of adding wind energy to the mix, it is possible that, during extreme low-load periods and subject to operating constraints on the plant, base load output may change somewhat. However, as the example above illustrates, the most expensive unit is generally the first to be curtailed. It is also important to emphasize that the graphs presented here mask a great deal of detailed data and variation in generator output due to wind energy. In the various simulations examined here, virtually all resources exhibited at least a small change when wind was introduced into the resource mix. The only exceptions are those resources and/or transactions that are fixed. For a few transactions, the total energy did not change but the timing of the transaction sometimes shifted. For resources priced at marginal cost, energy totals were largely unchanged, but the system marginal-cost differences due to wind caused a reduction in payments to the supplier. Part of the benefit that wind provides to the utility can therefore be traced to a reduction in payments to developers that qualify under PURPA, or other purchases that are priced at marginal cost.

Inspection of Figure 7 indicates that the wind resource is effective in reducing fossil fuel consumption. However, it is important to realize that there are many complex factors that drive the wind resource, and there are many complex factors that influence system loads. Figure 7 illustrates a fortuitous combination of system peak during a period of high wind power output. Figure 8 shows a contrasting case of system peak during a period of relatively low wind at wind site WC. The WC wind regime generates a small amount of power during the early morning and early evening, but is insignificant during the daily peak. Daily wind power from this site is not always so bleak during the summertime when utility Ul experiences its system peak. However, these two peakday graphs illustrate the wide range of conditions that can occur in periods during the system peak day.

From a long-range planning perspective, it is often useful to choose a reasonable, expected (in the statistical sense) base plan, looking at extreme variations to test the system's ability to handle the extremes. One simple approach to constructing the expected case is to calculate an average day in the utility's peak week. Figure 9 shows an hourly graph of this average day for utility Ul with a wind plant at the HP site. All values are averaged across the week for a particular hour, thus, the 3:00 a.m. value on the graph is the average of all 3:00 a.m. values for the week.

The hourly wind power generation in Figure 9 indicates that the peak-day wind power in Figure 7, while higher than the mean for the week, cannot be regarded as "atypical" for the peak week. The average generation from the conventional resources is probably not as interesting from a planning perspective, but does provide an important look at the mean generation requirements for the week.

Figure 10 shows the corresponding graph for the WC wind site. This average condition is clearly superior to the wind power realization on the peak day, i.e., it appears that the peak-day wind power is substantially below the 


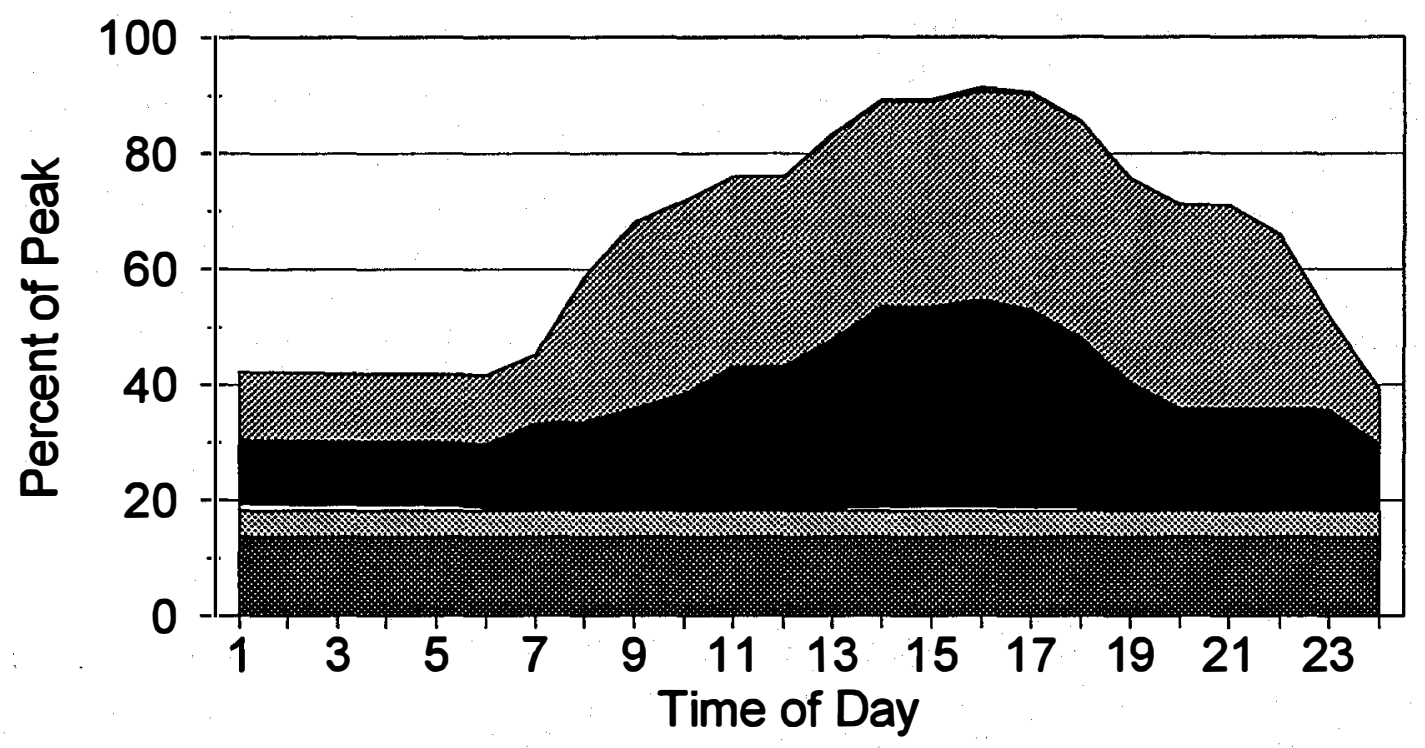

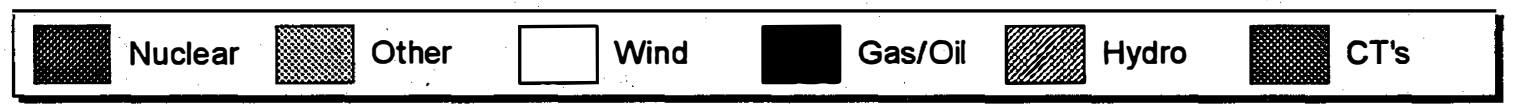

Figure 8. $\mathrm{P}+$ average day in peak week, utility U1, West Coast wind

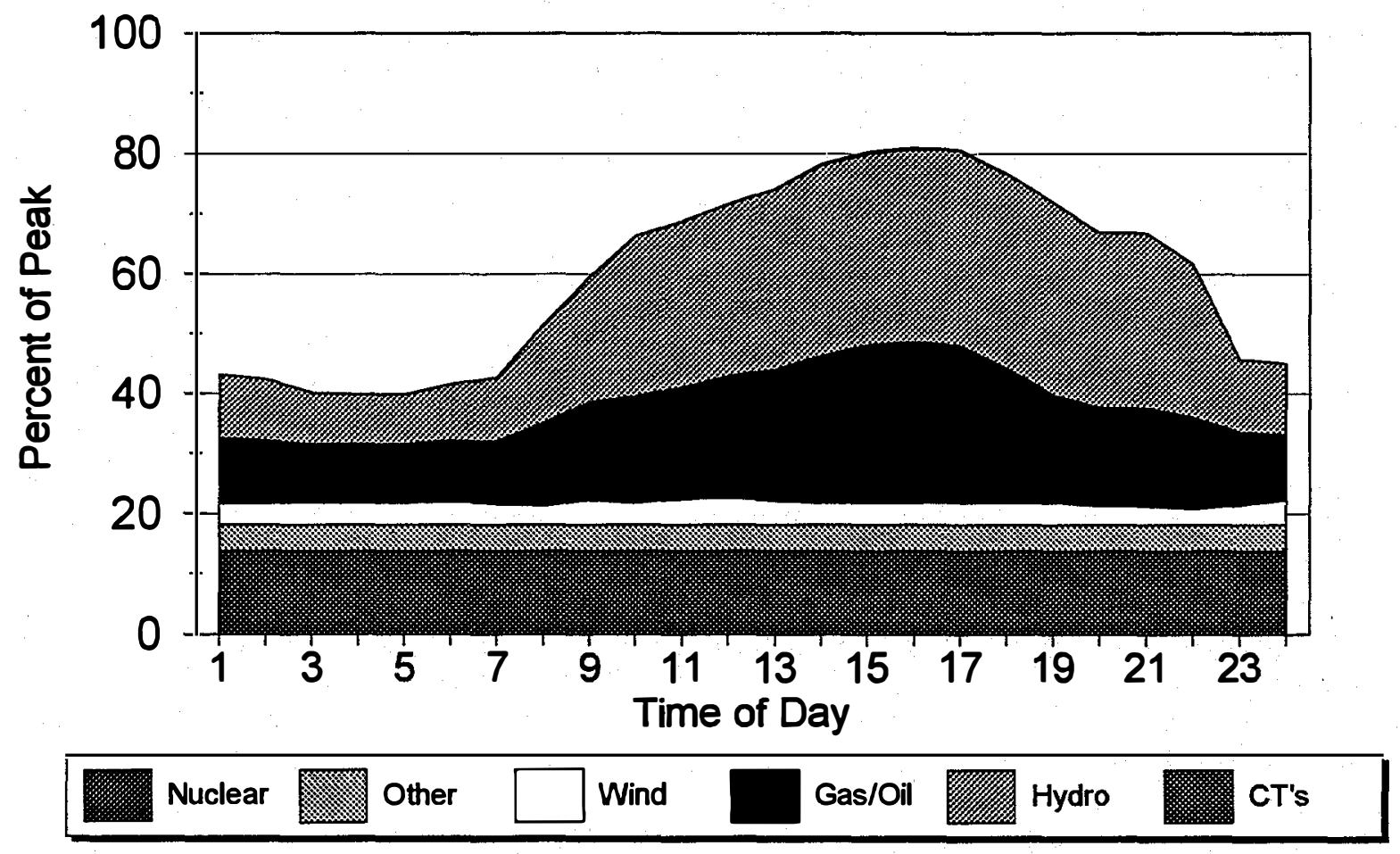

Figure 9. P+ average day in peak wek, utility U1, High Plains wind 


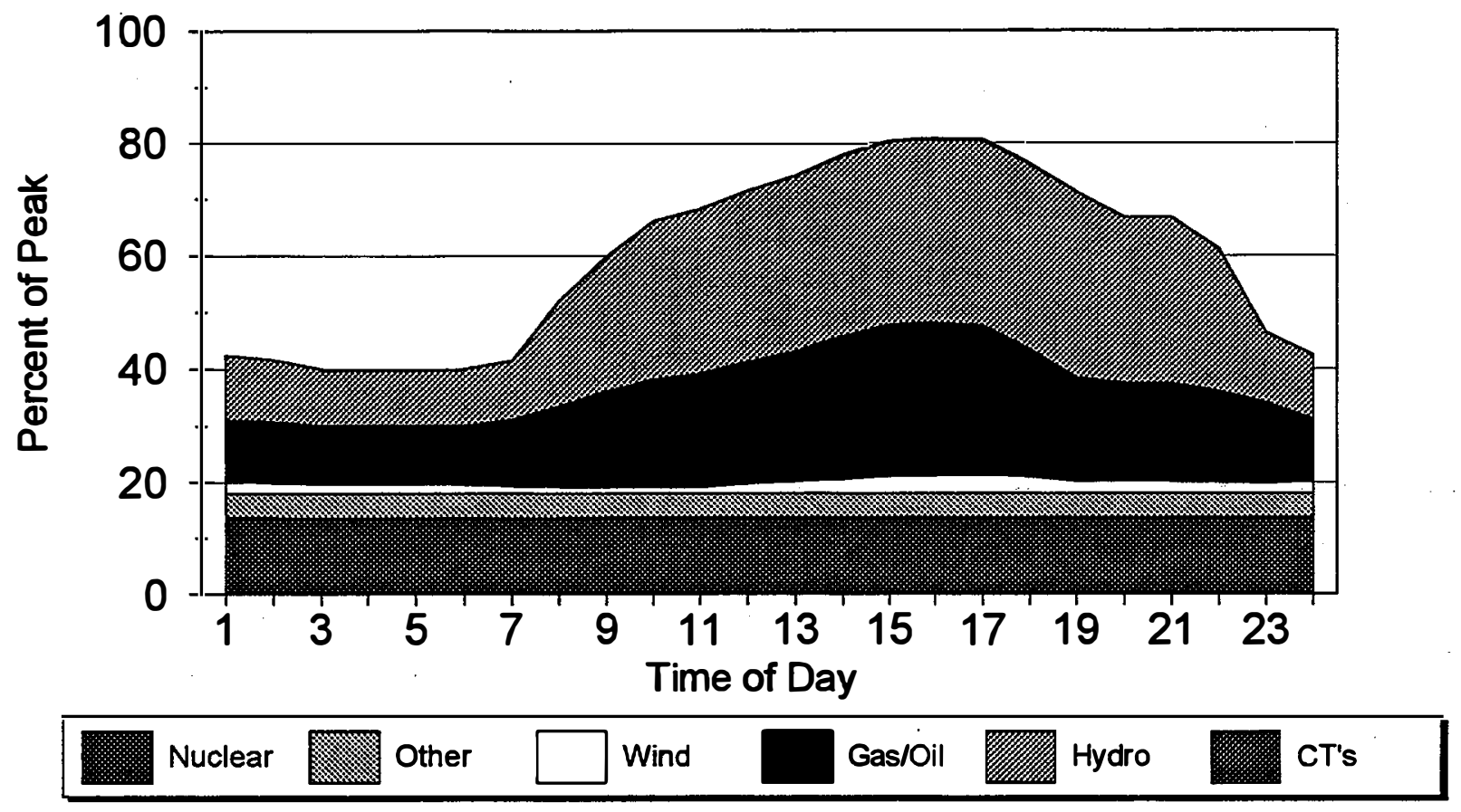

Figure 10. P+ average day in peak week, utility U1, West Coast wind

average daily value for the peak week. Although the wind power's contribution to the morning load pickup is not very high, it reaches its daily maximum just before system peak and continues until just after the daily peak begins its decline.

These simulations identify the generator fuel sources that can be reduced through the use of wind power. Figure 11 summanizes the change in the major fuels as a percentage of annual energy generated. The graph shows utility

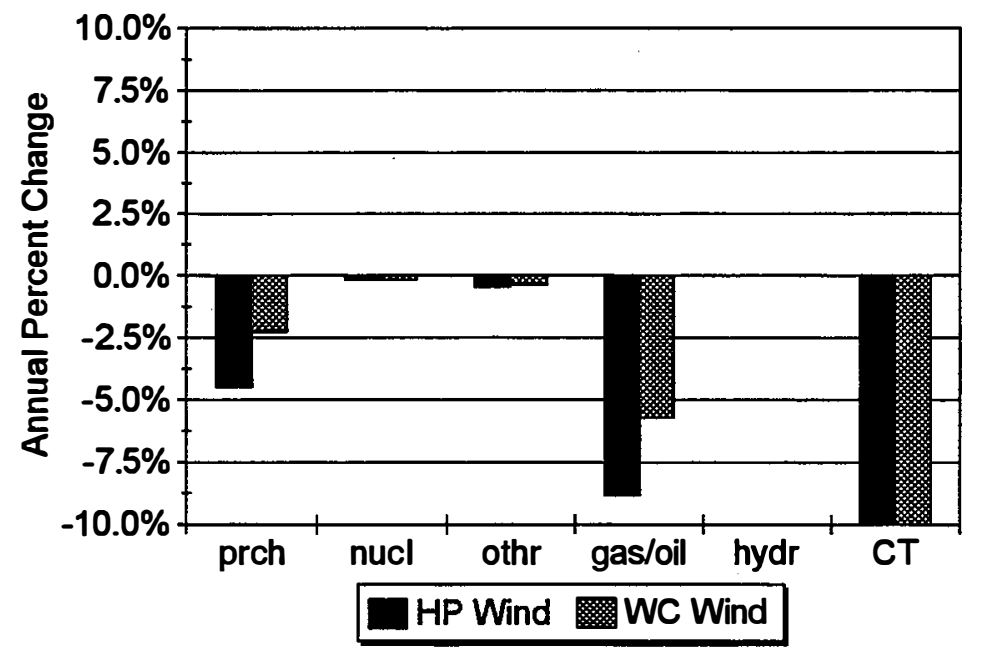

Figure 11. P+ comparison of wind/no-wind cases, changes in energy 
Ul for both wind sites using the no-wind case as the basis of comparison. Percentages less than zero indicate reductions from the base case.

Figure 11 shows the greatest reduction in combustion turbine (CT) and gas/oil generation. However, this percentage ranking distorts the CT generation, which is a very small portion of the annual mix of the utility. The most significant reduction is in the gas/oil units. These generators, along with the hydro units, are the ones normally used for load following. Because wind generation is used whenever it is available, the marginal loadfollowing unit, typically the most expensive for that hour, is reduced accordingly (last one on, first one off). The annual reduction in gas- and oil-fired generation ranges from about $5 \%$ to $8 \%$, depending on the wind regime. Base-load units experience extremely small changes, typically due to low-load times when wind power is available. Because these units are usually the least expensive or are subject to must-run constraints, the change in generation is insignificant. Utility $\mathrm{Ul}$ also can cut back on purchased power by approximately $1 \%$ to $3 \%$. The ability to reduce power purchases is highly dependent on the utility and the terms of its power purchase commitments.

Figure 12 explores the peak-day fuel reductions for the two wind regimes. For no wind, HP wind, and WC wind, the graph shows hourly generation from the gas/oil units. As one would expect, the WC wind site does not

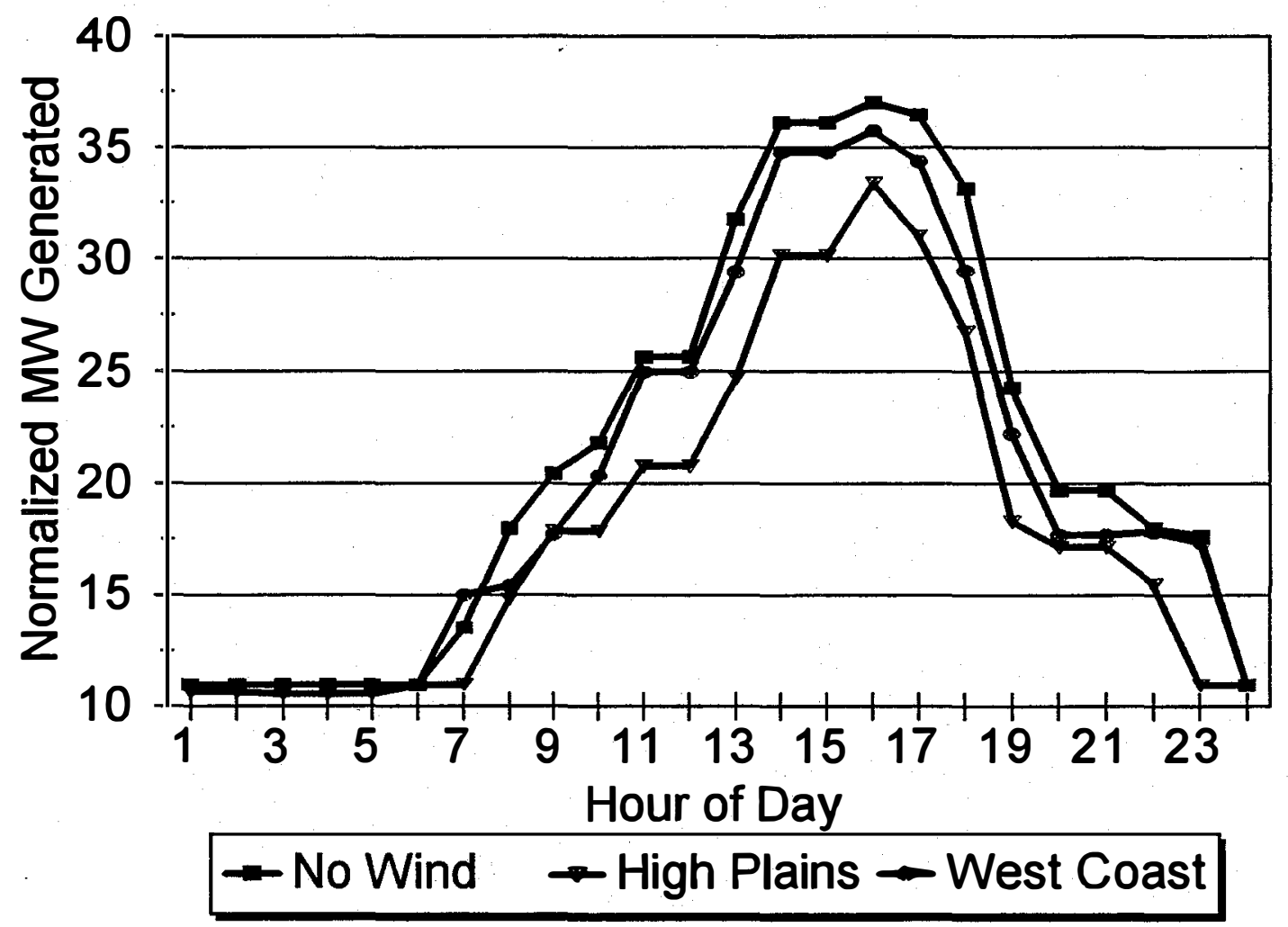

Figure 12. Utility U1 gas and oil comparison of peak day 
produce dramatic effects during the peak day, although it would do better on an expected day during the peak week. Conversely, the HP wind site shows a large decrease in gas/oil fuel requirements during the peak day.

For each model and method, the wind power benefit was calculated by taking the difference between the power production-cost of the base case (with no wind) and the production-cost of the relevant wind case. All costs were calculated for a single year. The benefits of wind power from the HP site, as calculated by $\mathrm{P}+$, can be summarized as a $4.1 \%$ reduction in operations cost for the year and a $49.3 \%$ reduction in annual LOLH. The WC wind case showed a $2.7 \%$ reduction in costs and a $65.3 \%$ reduction in LOLH. Although the HP wind provides more reliability on the peak day, the WC site does more to increase system reliability over the full year. If faced with a choice between these two sites, utility planners would noed to carefully balance the reliability needs and the economic returns offered by each site. It is also interesting to note that the wind site that provides the higher level of annual reliability provides a lower level of economic benefit. This occurs because the WC wind site has a better correlation to annual loads than does the HP site, but the latter provides more energy and thus more fuel savings.

\section{Elfin Results}

The Elfin model produces results that are very close to those of $\mathrm{P}+$. The load-modification modeling method is used for these Elfin nms, a method that parallels the one used with the $\mathrm{P}+$ model. Additional modeling techniques using Elfin are discussed below. The benefit of wind power for the HP wind case calculated by Elfin is $4.5 \%$, and the WC wind benefit is $2.6 \%$. Due to the nonchronological nature of Elfin, daily and hourly output is not available. However, the Elfin results are consistent with $\mathrm{P}+$ in that the output of the base-load units changes insignificantly when wind power is added to the system. The output does not change for the load-following units that are on the margin during periods of wind power. The following figures show the Elfin output that corresponds to the $\mathrm{P}+$ results above. In constructing these load duration curves, the capacity from each fuel type was weighted by availability, capacity, and commitment factors for the peak week (daily data are not available). Although these graphs cannot be viewed as precise pictures, they do illustrate the overall results.

Figure 13 shows the stylized annual LDC for the no-wind case. The horizontal axis represents the various subperiods used by the model. For all of these cases, the typical week of utility Ul was divided into six subperiods, corresponding to its peak, off-peak, and super-off-peak. During a simulation run, the model actually constructs a single load duration curve for each of the subperiods, performing the unit commitment and economic dispatch for each subperiod. The graphs that follow represent linear interpolations of the results of each of these load duration curves. The various base-load units have constant output, whereas the oil/gas and hydro units perform the load-following function.

Figure 14 illustrates the HP wind case. As indicated by the diagram, the load-following units reduce their output in response to the additional wind power on the system. As with the $\mathrm{P}+$ run, the contribution of the wind plant during the system peak is significant. This is illustrated by the size of the wedge under the gas/oil generation. Of course, year-to-year variations in the wind power contribution to peak are to be expected. 


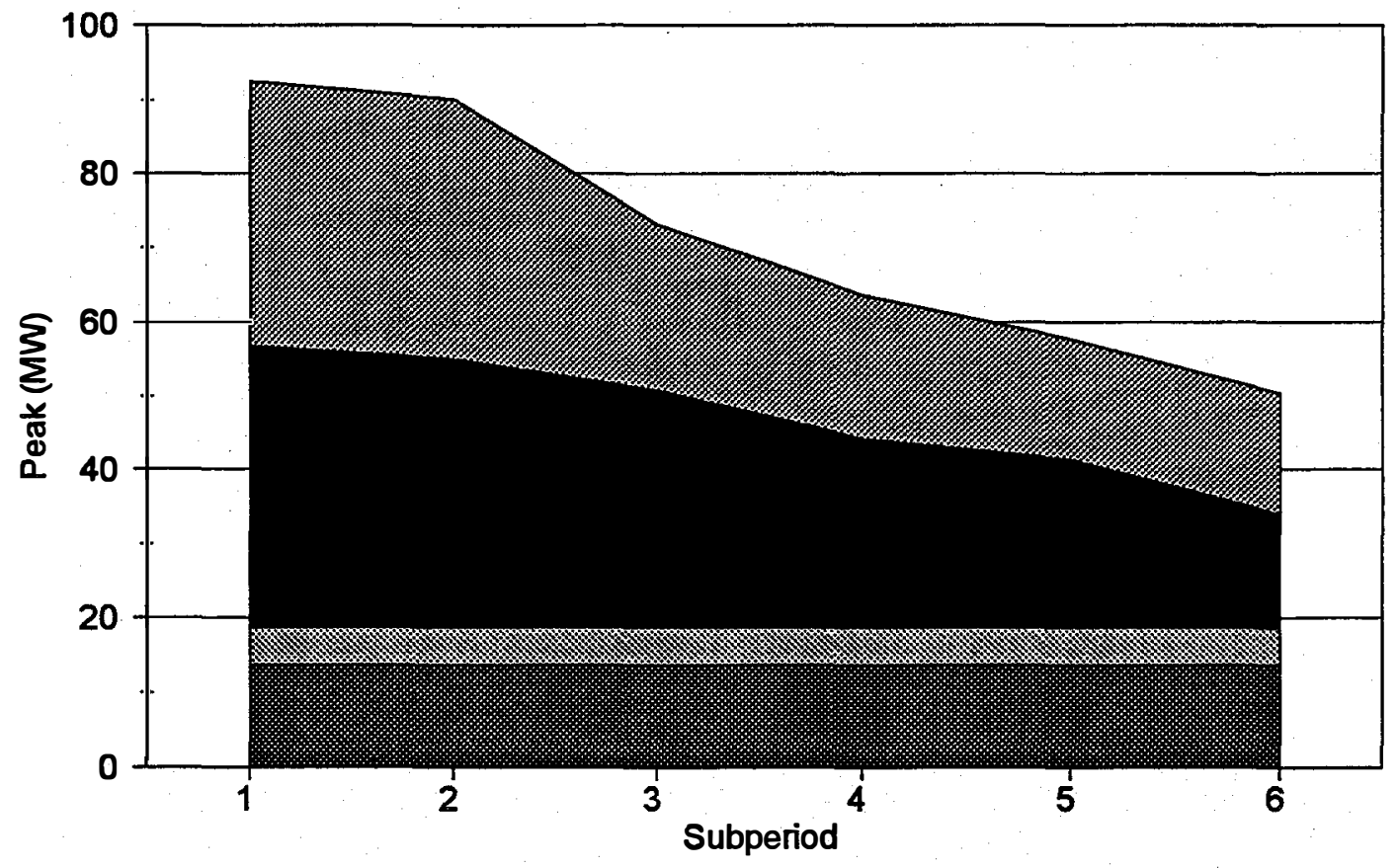

Nuclear Other Gas/Oil Hydro

Figure 13. Elfin peak-week subperiods, utility U1, no wind

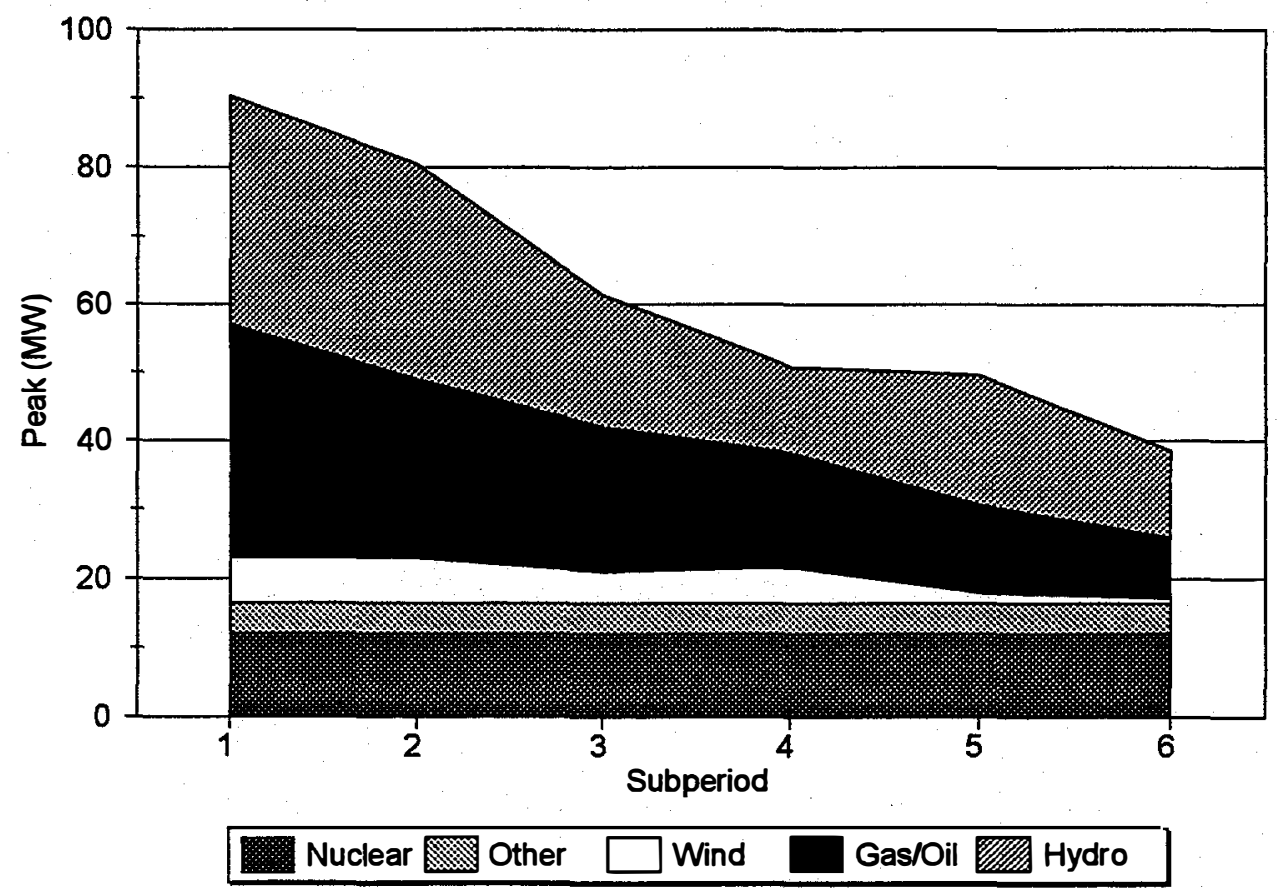

Figure 14. Elfin peak-week subperiods, utility U1, High Plains wind 
Figure 15 also supports the results of the $\mathrm{P}+$ model. Here, the diagram indicates that most of the reduction in gas/oil generation occurs off-peak, resulting in a smaller "tail" for hydro and gas/oil units. This is most visible in subperiods 4 and 6.

Wind power also was modeled in Elfin using two supply-side representations of the wind plant. The first of these, the simplistic supply-side approach, used the same time-varying wind generation schedule as the loadmodification approach. When Elfin converts the chronological load and resource data to the load duration curve format, wind power from all hours for the given subperiod is averaged. Some temporal resolution is lost, and the statistical variance of the wind resource is significantly reduced. No attempt was made to use the unit forcedoutage rate to approximate additional variation from the wind resource because that information is embodied in the varying hourly wind power output.

The second supply-side option models the wind plant as a multiblock thermal unit, but without thermal-specific data such as heat rates. Wind plant output is binned, according to the various inflection points on the turbine power curve, and a family of wind-speed probability distributions is calculated. For each month, we construct 1 typical day. This typical day is composed of one probability distribution per hour, resulting in 24 probability distributions per typical day. Each of the probability distributions is calculated based on all available data for the month. The result can be interpreted as a probability distribution that describes wind power availability for each hour of a typical day per month. Therefore, we have 24 probability distributions per month, one per hour of the day, and $12 \times 24=288$ probability distributions for the full year. Figure 16 illustrates a time-dependent probability distribution for a typical day in January for the WC wind site.

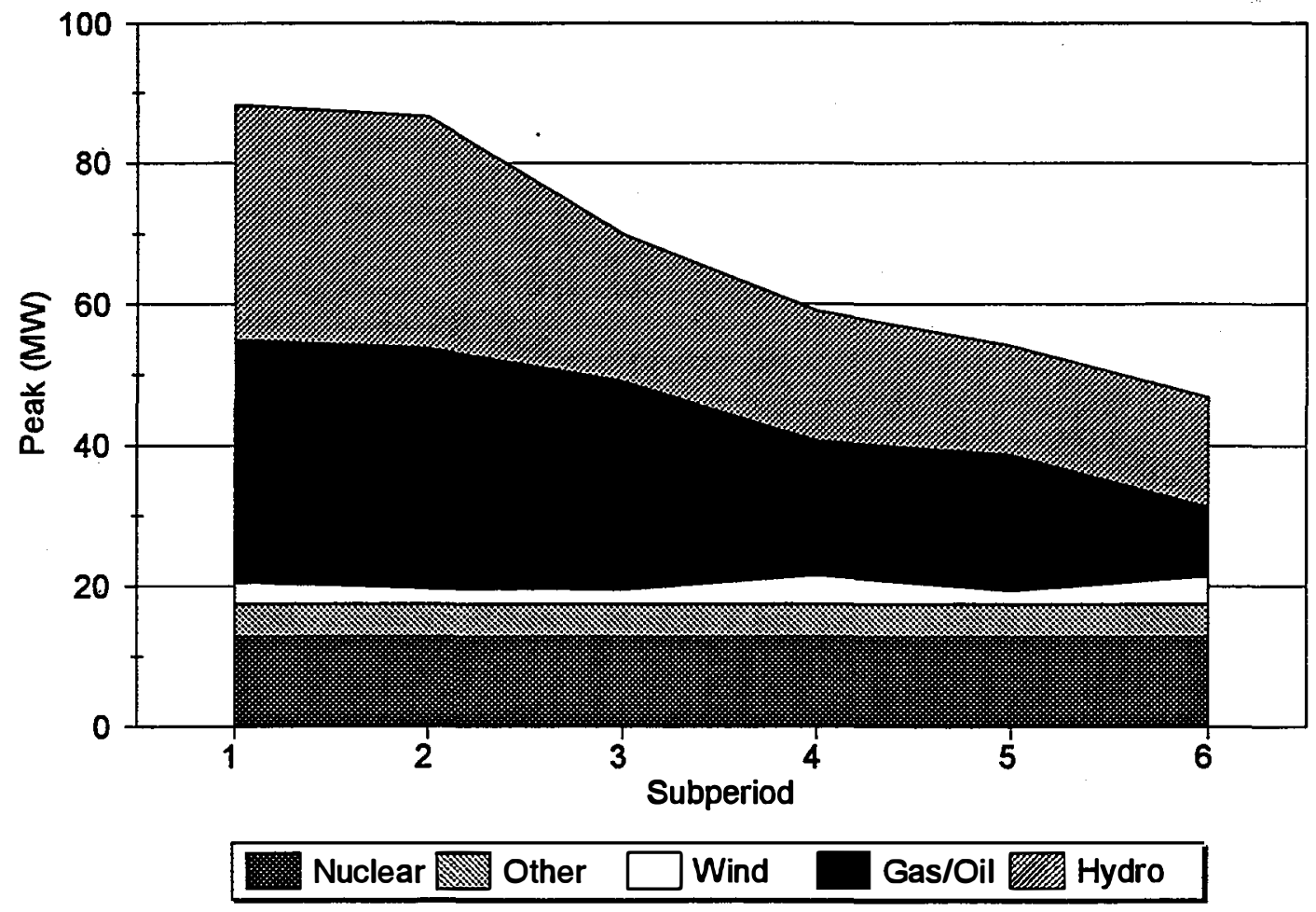

Figure 15. Elfin peak-week subperiods, utility U1, West Coast wind 


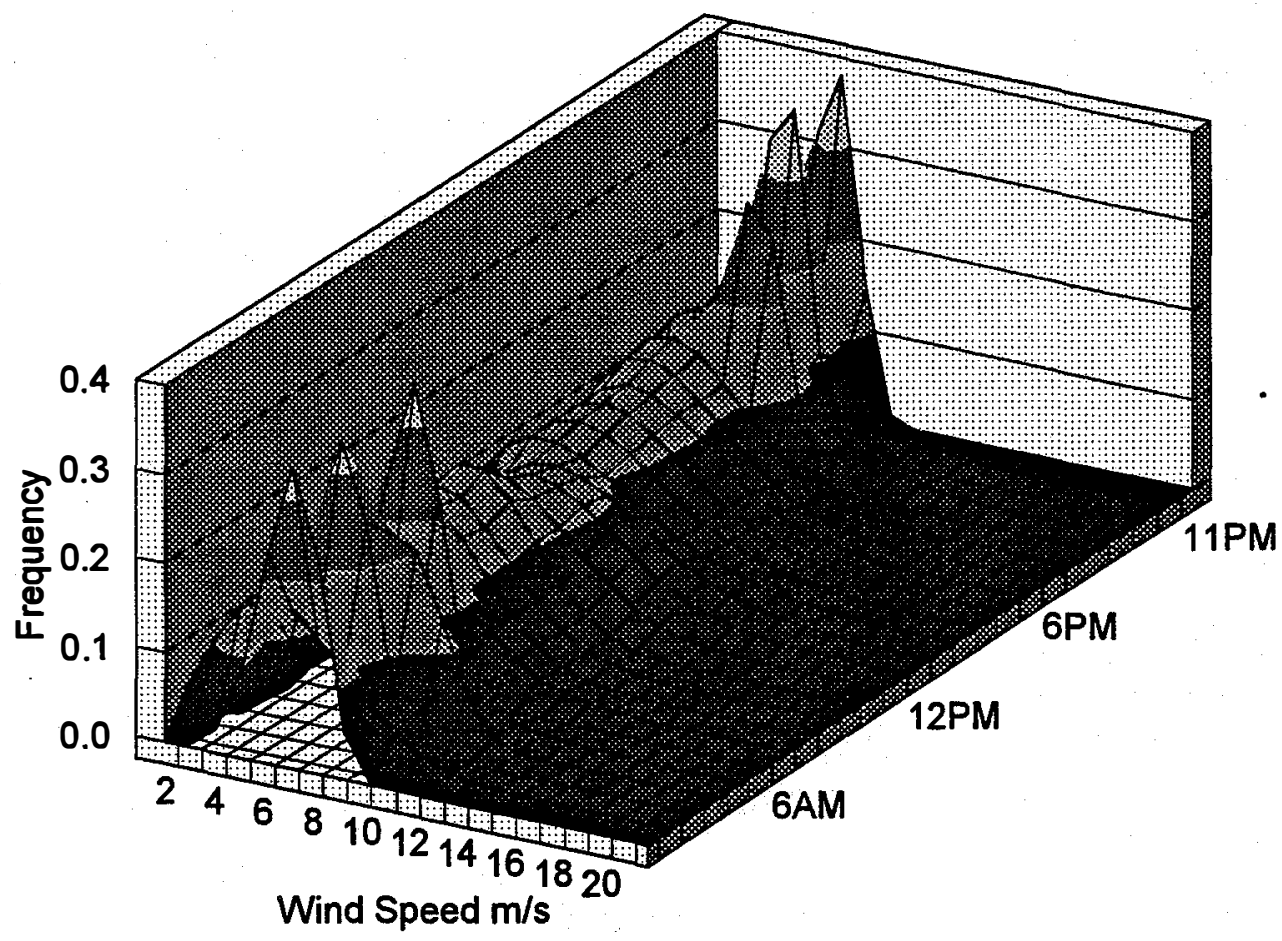

Figure 16. Probability surface for a typical day in January, West Coast wind

Consolidating all these methods results in the following sets of model nuns. With Elfin, wind is modeled as a load modifier, a time-varying supply-side resource, and a multi-block supply-side resource. With $\mathrm{P}+$, wind is modeled as a transaction, which is equivalent to a load modifier. Simulations were run for each of the two utilities and wind sites using the four modeling methods.

Figure 17 shows the percentage reduction in annual costs that result from adding wind generation to utility U1. The graph shows the results from the Elfin time-varying capacity (CP), load-modification (LM), and multiblock probabilistic (PR) methods. The last bar shows the $\mathrm{P}+$ results.

The three Elfin cases clearly produce similar results - cost savings (benefits) in the 4-5\% range. Conceptually, the Elfin LM case most closely parallels the P+ case because it offers the greatest degree of temporal resolution, and deducts wind power before performing the commitment and dispatch algorithm. Comparing these two cases, we see that the P+result shows a slightly smaller benefit than the Elfin LM case, $4.1 \%$ versus $4.5 \%$, respectively.

Figure 18 illustrates the corresponding results from the WC wind site. The same relative relationships between the various Elfin modeling scenarios are apparent, with the Elfin LM case yielding a $2.6 \%$ benefit compared to the $2.7 \%$ benefit of $\mathrm{P}+$. 


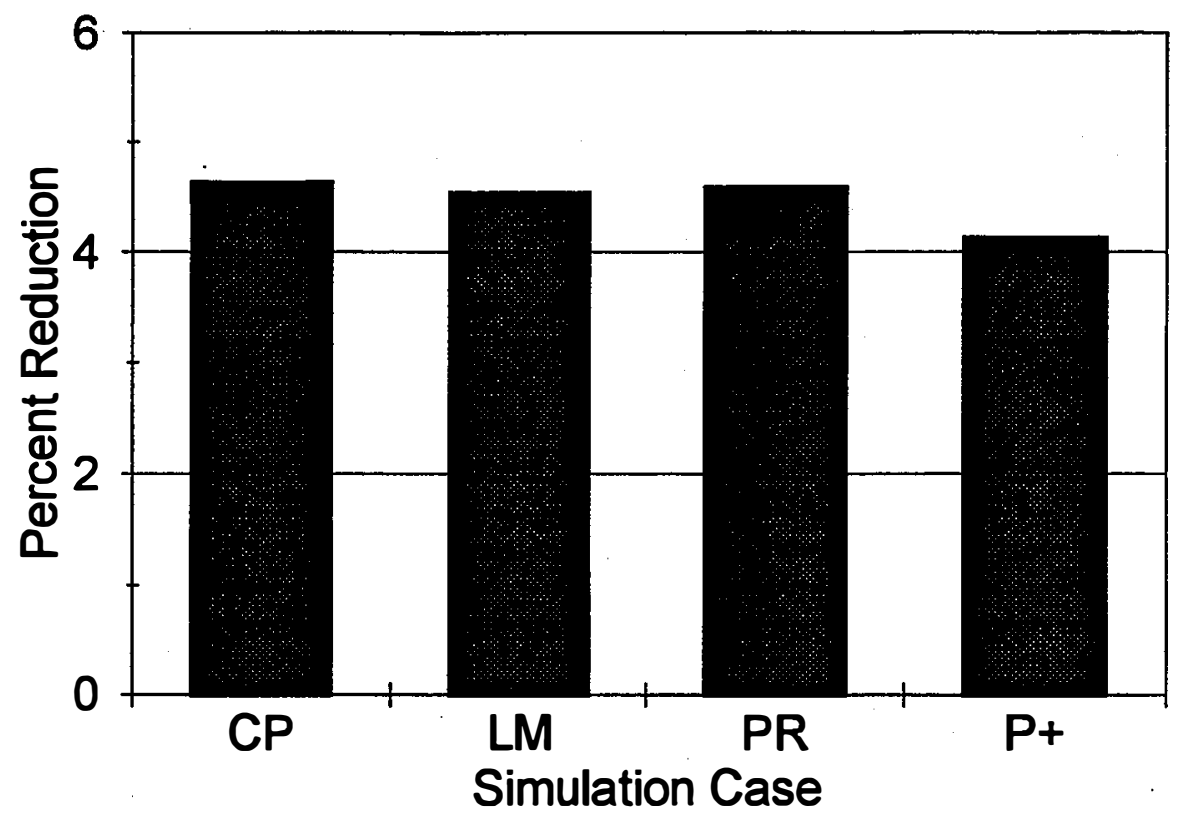

Figure 17. Cost reduction from base case, High Plains wind, utility U1

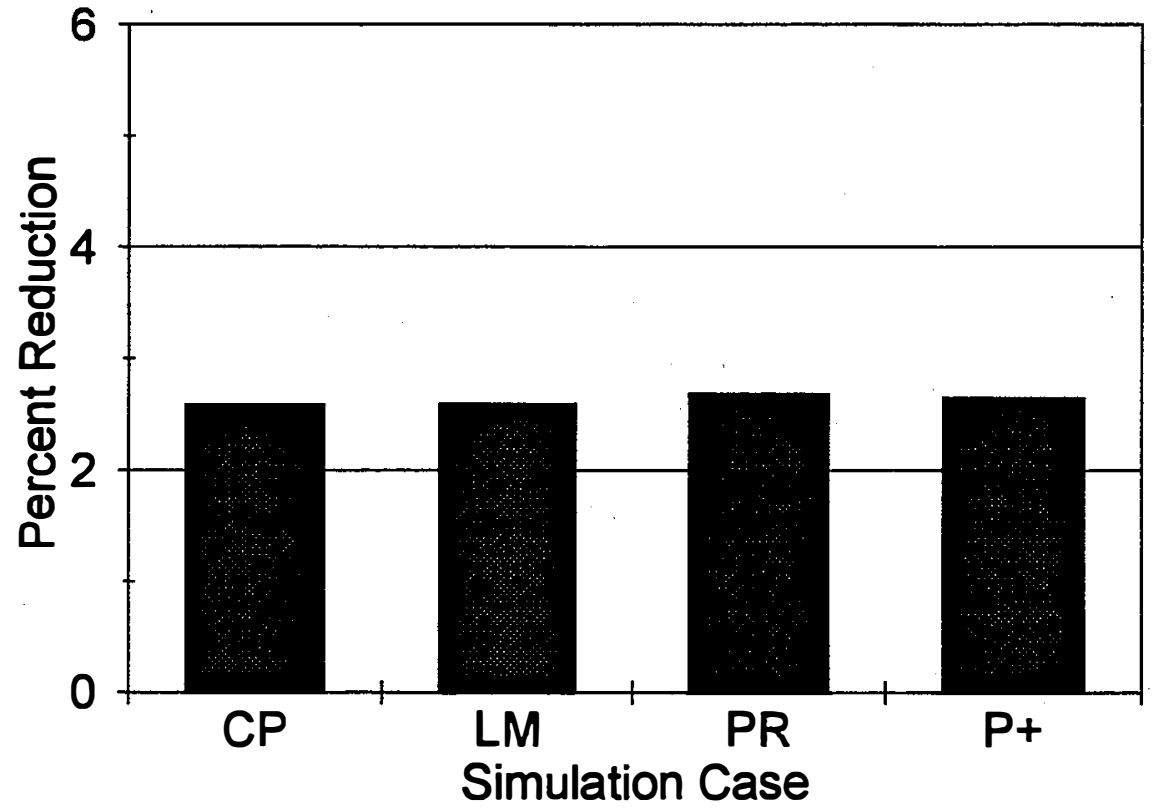

Figure 18. Cost reduction from base case, West Coast wind, utility U1 


\section{Comparison of Model Results}

The P+ model calculates less of a benefit for wind power in the HP wind case than does the Elfin model. This implies that the change in generation calculated by $\mathrm{P}+$ is less than that of Elfin Because the base load units and combustion turbines experience an insignificant absolute change, that leaves only the load-following units, the gas/oil generators, to compensate for the addition of wind power. Figure 19 illustrates the change in this group of generators. Indeed, the $\mathrm{P}+$ results indicate a smaller change in the gas/oil units than in the Elfin cases.

Two hypotheses may explain the divergence in results between the two models. First, we have not provided P+ with ramping rates. Therefore, start-up costs for slow-start units are not considered. The P+ output indicates that the number of starts and stops of gas/oil units is significant-approximately 700 unit start-ups annually are eliminated with both the $\mathrm{HP}$ and $\mathrm{WC}$ wind for utility $\mathrm{Ul}$. Including ramp rates and other start-up information would cause $\mathrm{P}+$ to calculate a larger benefit for wind power.

The second hypothesis is that, due to the chronological nature of the $\mathrm{P}+$ model, constraints on unit commitment may be somewhat exaggerated by the Elfin model compared to the P+ model. For example, Elfin performs its commitment algorithm for each week, separating the weekdays from the weekends. Committed plants are assumed to be committed for the week, although they may be decommitted for the weekend. ${ }^{11}$ The P+ model decommits each plant whenever possible, subject to ramping constraints. It is likely that when the Elfin commitment constraints are binding (i.e., units cannot be decommitted during low-load periods), the commitment list calculated by Elfin differs significantly from the dynamic commitment list calculated by $\mathrm{P}+$. Of course,

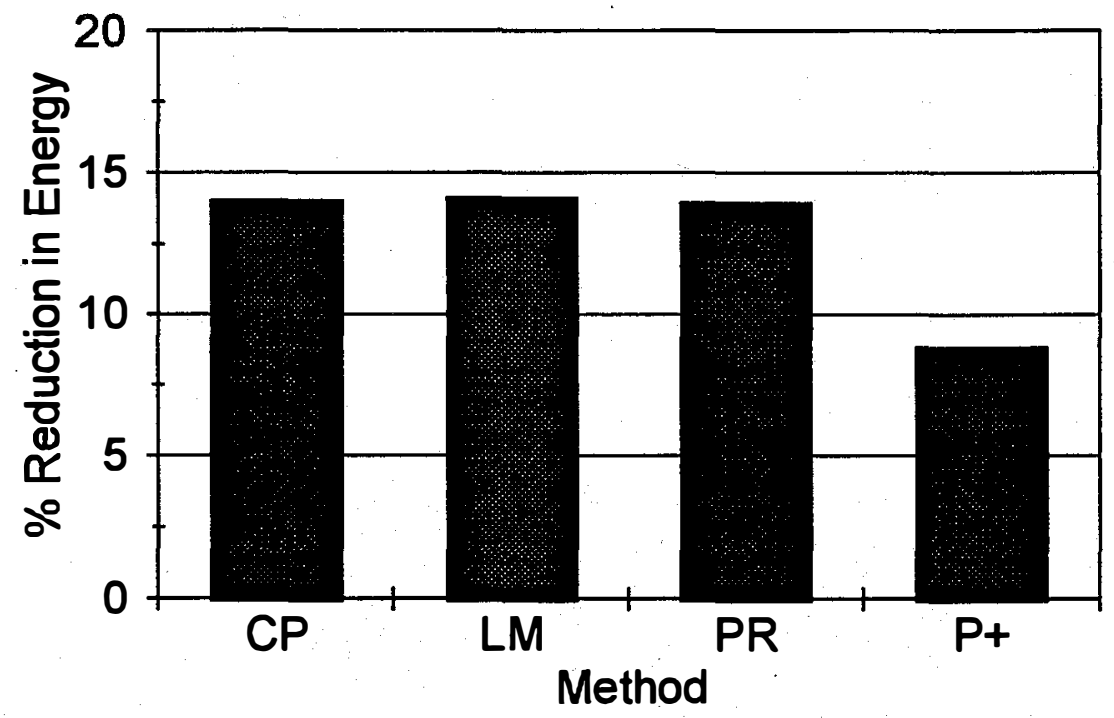

Figure 19. Change in energy from gas and oil units, High Plains wind

${ }^{11}$ This story is complicated somewhat if the user chooses the probabilistic commitment algorithm instead of the deterministic commitment algorithm. Although both commitment options were run for this study, cost differences between the two methods were insignificant. 
commitment differences will lead to dispatch differences, resulting in the different cost estimates and wind benefits calculated by each model.

Both models calculated the overall reliability of the system. The P+ reliability tool was not used in this study, but the production-cost module calculates operating reliability during the production simulation. The $\mathrm{P}+$ production-cost program uses the method of cumulants, whereas Elfin uses a piecewise approximation to the load duration curve. During the model calibration phase of this project, production-costs of the no-wind cases for each model agreed to within about 3\%; however, the reliability measures produced by the models did not agree to within an order of magnitude. The relative changes in reliability that each model calculated as a result of adding wind generation were surprisingly close, as indicated by Figures 20 and 21 . It is not clear from this exercise which of the reliability estimates is the most accurate. The accuracy of the chronological model must be balanced against the accuracy of the piecewise approximation used by the LDC model. It is clear that the relative changes in reliability induced by wind power calculated by each model are in agreement. One goal of future work should be a complete analysis of the desirable properties and uses of a reliability tool, and the implications for intermittent resources such as wind.

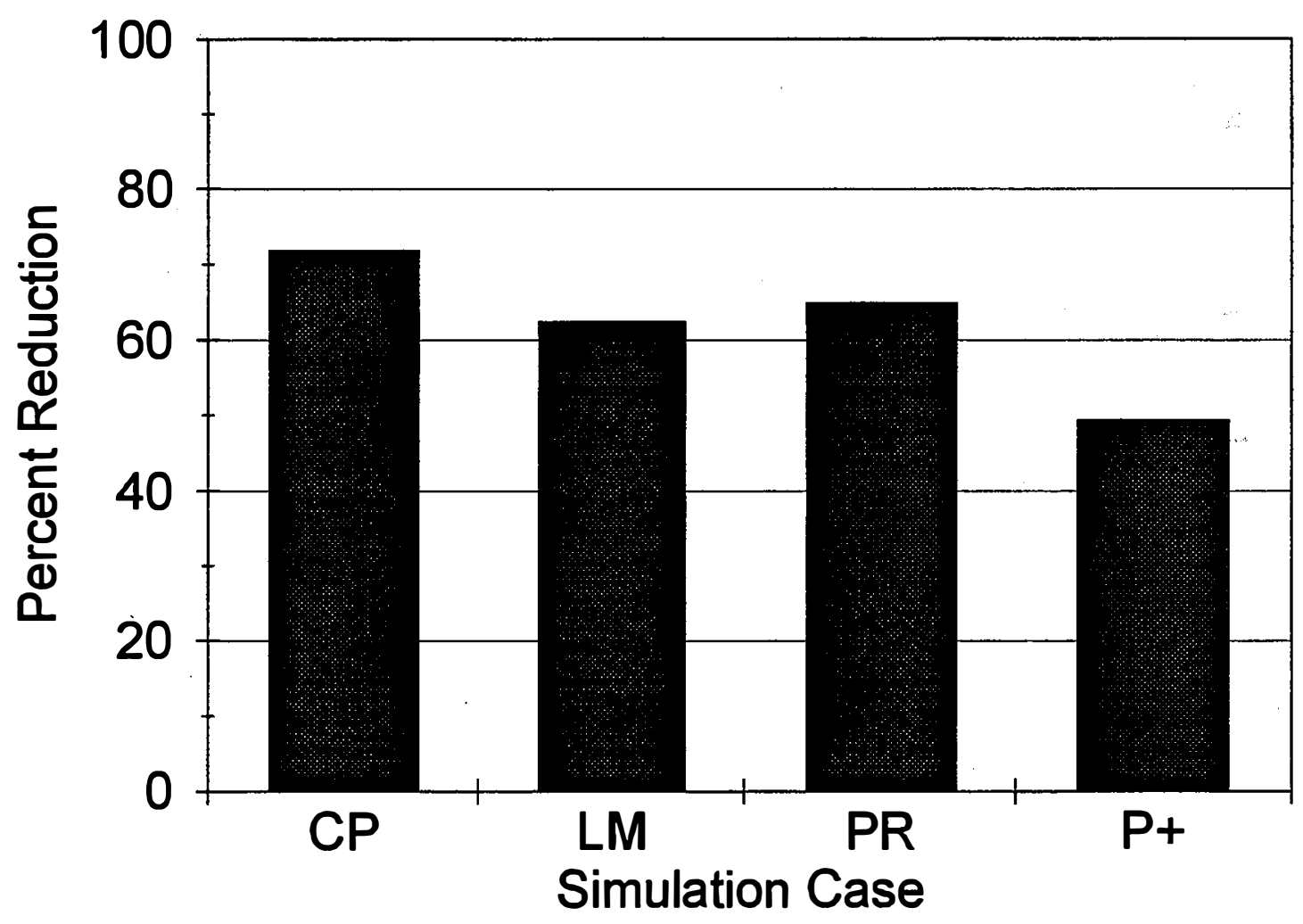

Figure 20. LOLP reduction from base case, High Plains wind, utility U1 


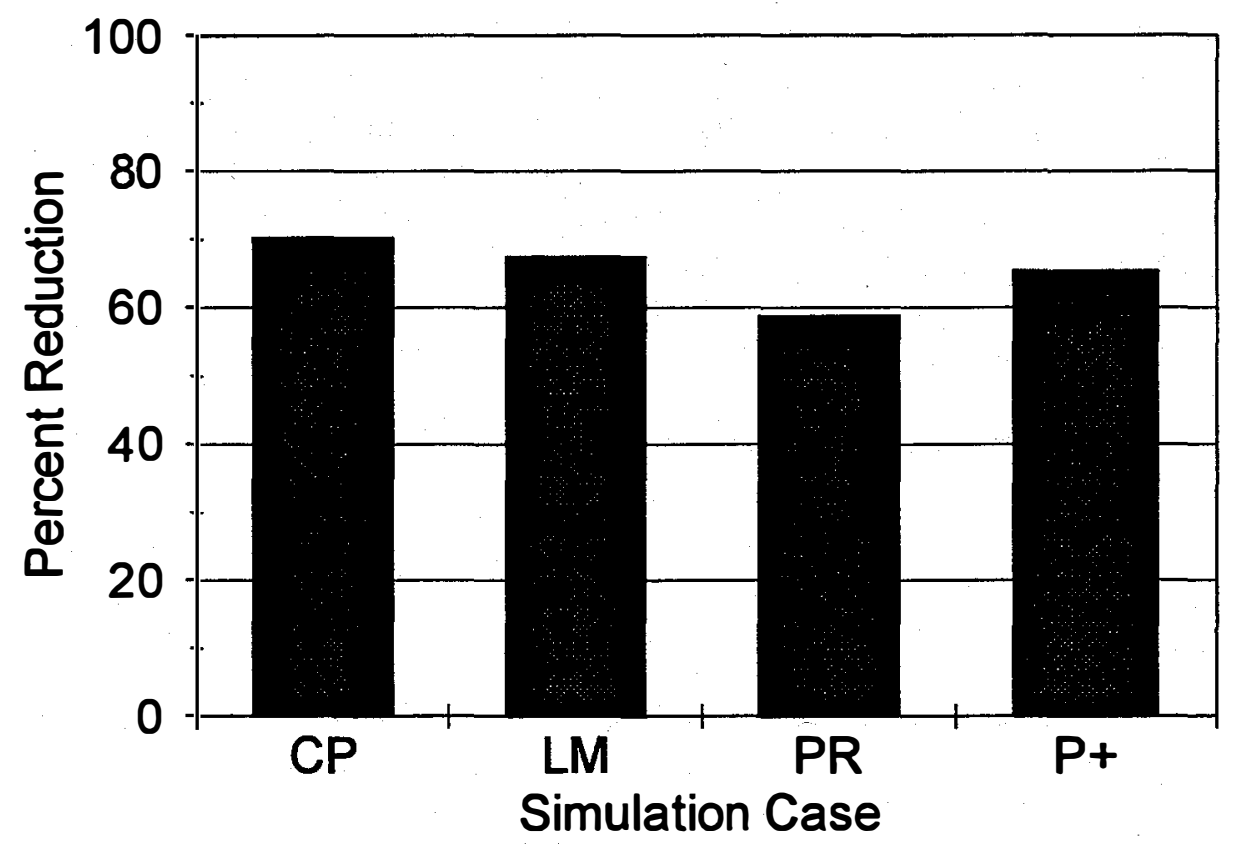

Figure 21. LOLP reduction from base case, West Coast wind, utility U1

The discussion thus far has revolved around utility U1. The analysis and model runs also were performed for utility U2, and the results were not significantly different. Base-load generation was not displaced by wind power (except for extreme low-load periods), and most of the energy displacement occurred with the gas/oil units. The calculated benefit of wind power between the two models was again very close when the load-modification method of Elfin was compared to the P+ results. Rather than repeat the discussion of utility U1 for utility U2, some relevant graphs of the $\mathrm{U} 2$ results are presented in the Appendix.

\section{Off-Peak Results}

A great deal of analysis of wind plants focuses on system peak effects and impacts. The motivation for this attention results from the utility's obligation to serve its load, and the peak period presses all available resources into service. Resource needs during peak periods drive the system reliability measures. However, the choice of resources used on-peak has an important effect on off-peak costs. Given the classic trade-off between building a quick-start combustion turbine and a slow-start steam boiler, the decision maker must weigh a high fuel costlow capital cost resource with a low fuel costhigh capital cost resource. The slow-start unit likely imposes an overhead cost - the cost of spinning at its minimum load level during low-load periods. This type of cost has long been recognized. ${ }^{12}$

12 See J.M. Clark (1923). 
Chronological transition between the peak and off-peak periods occurs as the utility control center reduces the output of the load-following units, subject to ramping and minimum run constraints. Both the Elfin and $\mathrm{P}+$ models take these off-peak periods into account, as will be discussed below. However, it is interesting to examine some plausible scenarios that can occur off-peak for a utility with significant wind generation.

From a power-system-scheduling perspective, the optimal situation occurs when a new wind plant can eliminate the commitment of a conventional unit. For this happy state of affairs to occur, the wind generation must displace the conventional unit during all the hours that the conventional unit is needed. Displacement need not occur during the hours that the conventional unit is not needed and running at minimum load. In terms of off-peak commitment effects, this total displacement can take place only if the generation mix is not operating at its minimum load level. The maximum economic benefit of wind power is realized when conventional unit commitment can be avoided.

Suppose that a utility nms its system at minimum load at night (say, midnight to 5:00 AM) and just covers load plus spinning reserve. Such a situation might be represented by Figure 6 . Now suppose that significant wind generation is available during these nighttime hours. In this case, wind energy is not beneficial because it cannot be used. The conventional units that were needed during the peak periods (and will be needed for the next peak period) cannot be run at a lower output level and cannot be shut down. The wind energy is spilled unless it can be stored or sold in the wholesale power market.

The Elfin model performs its commitment scheduling on a weekly basis. Slow-start units that are needed during the week can be nun at minimum load levels, but they remain committed for the week. ${ }^{13}$ The commitment target is set for each week and is typically equal to the peak load plus a reserve percentage. The commitment algorithm ensures that there is sufficient capacity from spinning slow-start plus quick-start units to meet the commitment target for each subperiod of the week. If the sum of committed units falls short of the target during the peak subperiod, this shortage will extend into off-peak periods. Injecting wind energy into such a system will not reduce conventional commitment because the additional wind capacity is needed to meet the target. However, the additional on-line capacity will increase the system reliability level.

The $\mathrm{P}+$ model calculates commitment on an hourly basis. The equivalent load is calculated by deducting firm transactions and hydro generation. The remaining load, plus reserve requirement, is the commitment target. If the currently committed units cannot meet the target, the next-least-expensive unit is committed. This process continues until either the target is met or there are no more units left to commit. During periods of declining load, the process works in reverse. The commitment target is calculated and compared with the committed generation. If the generation is too high, the most expensive unit can be decommitted after checking to make sure it will not be needed in the next few hours. During the late-night hours, the commitment target is just equal to the load plus reserves. Even if the commitment target cannot be met during the peak hour(s), it can likely be met during the off-peak periods. Injecting wind generation into such a system could still reduce commitment during these offpeak periods.

To investigate some of these effects, we modified the utilities' loads so that commitment targets could easily be met during off-peak periods. However, these two utilities have additional constraints (voltage support, transmission, and other regional requirements) that may prevent the decommitment of certain units during low-

${ }^{13}$ Units can be specified to be weekend constrained if desired. 
load periods. ${ }^{14}$ A detailed investigation of these constraints and the extent to which wind generation can mitigate them is beyond the scope of this study. The results presented here do account for these minimum constraints, which translate into a reduction in the potential benefit of wind power.

At lower load levels, a utility will scale back on the operation of its most expensive resources, causing a reduction in marginal cost. This reduction is likely to occur for each hour of the year as long as the new load is less than the original load. Because wind generation displaces generating units on the margin, it should come as no surprise that, at a lower load level, wind contributes a smaller economic benefit than it would at a high-load level. Figure 22 shows this to be the case for utility U1. Approximately the same relative relationships hold between the various simulation cases. All of the other cases show similar results-a benefit hovering near $3 \%$ of production-cost. Comparing this to the benefits from the earlier cases, we see that the wind benefit has declined from approximately $4.5 \%$ in the high-load cases to about $3 \%$ in the present cases. Figure 23 shows a similar situation. The benefit of wind has declined from about $2.5 \%$ in the earlier cases to approximately $2.0 \%$ (or slightly below). The implication of these results is clear: The level of benefit that is calculated by productioncost models is quite sensitive to the load forecast used in the study.

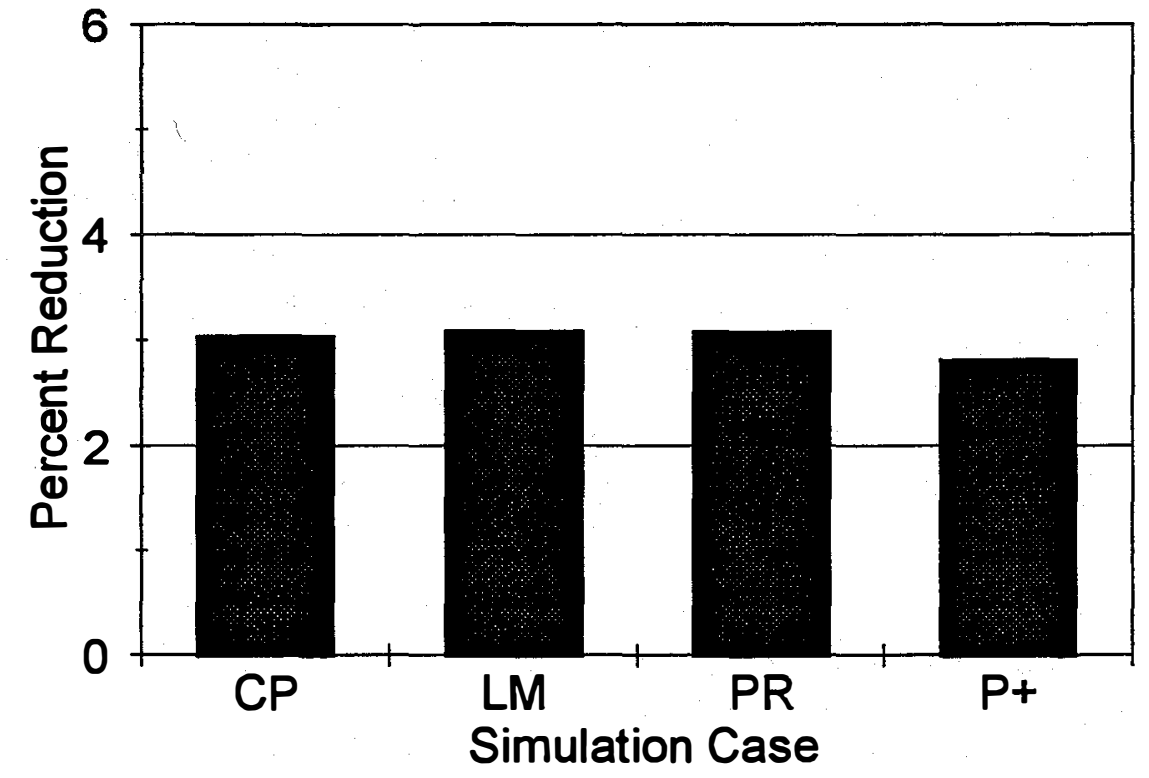

Figure 22. Cost reduction from base case, High Plains wind, utility U1, low loads

${ }^{14}$ These constraints are in addition to the normal operating constraints on certain slow-start generating units. 


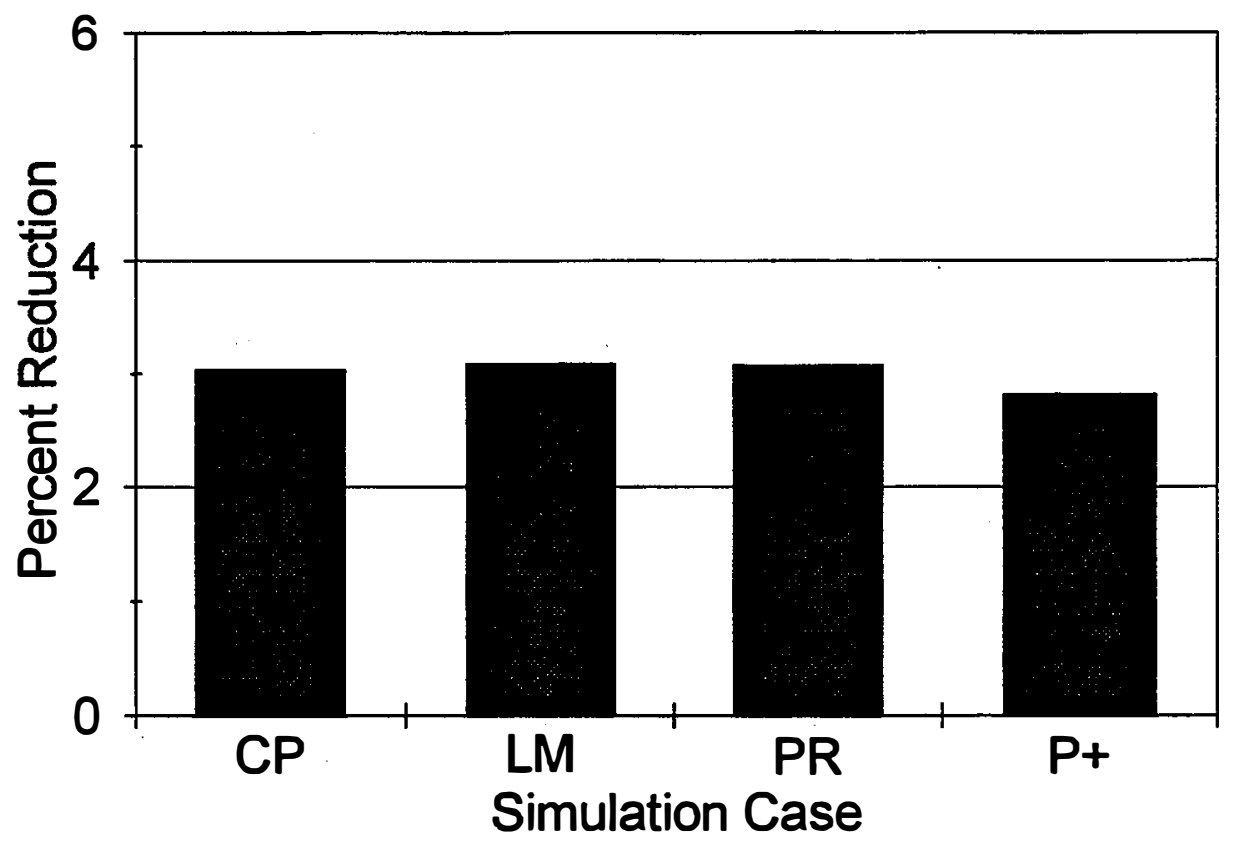

Figure 23. Cost reduction from base case, West Coast wind, utility U1, low loads

To illustrate some of the off-peak results, we selected a weekend period during the peak week for utility Ul. The $\mathrm{HP}$ wind resource provides substantial variation during this period, reaching both maximum and near-minimum values during the day and night. Figure 24 shows traces for the weekend in question, illustrating the wind power and utility load for each day of the weekend period. The $\mathrm{P}+$ output shows that, in general, high-wind hours cause a reduction in conventional unit output. In some instances, units spinning in the no-wind case are not needed in the wind case. During the 1:00 a.m. hour of Sunday, the wind plant reaches its maximum output for 1 hour before declining to $37 \%$ in the following hour. During the high-wind period, virtually all spinning units are running at reduced power output, and even the output of the nuclear units is reduced slightly. As wind output drops, these units spin at a higher output level. While the wind output is at maximum, additional charging for the pump storage units is possible, raising an interesting question about the value of time-shifting wind power from offpeak periods to peak periods via storage. During a few of the nighttime hours, when wind power exceeds $20 \%$ of maximum, additional spinning units can be shut down. To the extent that this is possible, the overhead cost of spinning is reduced. During the 5:00 AM hour of Sunday, P+ calculated that $1 \mathrm{MW}$ of capacity had to be dumped. The wind output for that hour is approximately $20 \%$, and the dumped energy is extremely small. However, given the usual operating constraints faced by utilities, this example illustrates the potential for generating dump energy during low-load periods.

The relevant marginal costs that are offset by wind are difficult to define and measure. We calculated these costs by nnning a production-cost model with and without wind and treating the difference as the benefit. However, these results are also sensitive to the number of plant shutdowns made possible by the wind resource and the allocation of avoided start-up costs. This is one reason that the wind benefit is sensitive to the load level. At high-load levels, introducing a wind plant into the generation mix may cause high-cost units to be curtailed and lower cost units to be run at a reduced output level. A further increase in the wind resource, or reduction in 


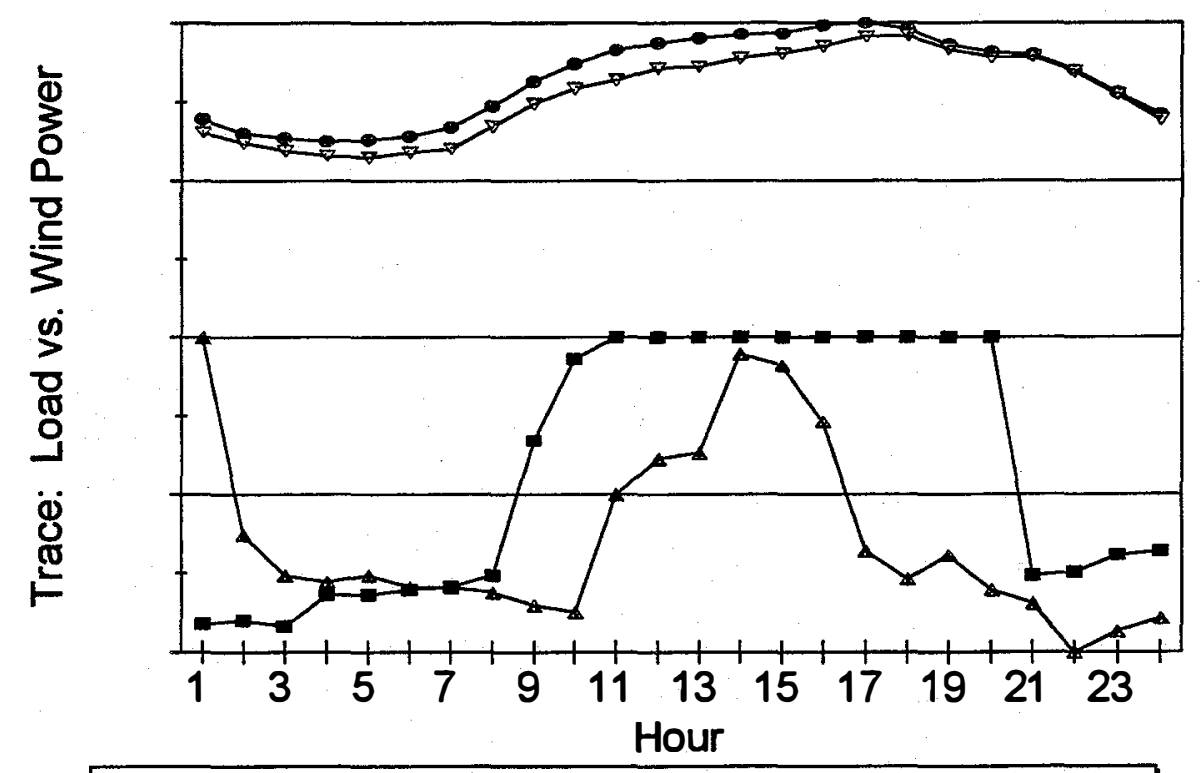

$\rightarrow$ Sat. Wind $\rightarrow$ - Sun. Wind $\rightarrow$ Sat. Load $\rightarrow$ Sun. Load

Figure 24. Weekend load, High Plains wind, utility U1, low loads

load, may make decommitment of slow-start units possible. It is at this point that the modeling techniques become important because the difference in commitment and decommitment algorithms causes alternative units to run in the simulations. To the extent that start-up costs are significant and included in the simulation, the marginal-cost curve will likely be "lumpy" around the point at which unit start-up occurs if start-up costs are included in the definition of "marginal cost" used by the model/utility/planner. Marnay and Strauss (1989), for example, list 12 variations of plausible marginal-cost definitions. ${ }^{15}$ Production-cost models calculate the expected plant output after accounting for various outage rates. The result will almost always be different from the actual generation schedule, in which units are actually out of service and have actual output of zero. The expected marginal cost calculated by the model is, of course, based on the expected plant outputs. Therefore, actual marginal cost will vary according to which plant(s) is (are) out of service.

In reviewing the Elfin weekend results, it is important to distinguish Elfin's time-step from the P+ chronology. With Elfin, the weekend is divided into two subperiods: peak and off-peak. The commitment level is based on calculating the target during the peak period, then committing whatever slow-start units are needed. Because some of these units cannot be decommitted during the weekend, Elfin cannot adjust commitment during the nighttime off-peak period if there is significant wind power on the system. During the off-peak period, we have approximately $200 \mathrm{MWa}$ of excess committed capacity over the no-wind case. As in the P+ simulation, Elfin is able to shift some of the pump-storage charging as a result of the available wind power.

${ }^{15}$ We conveniently ignore the extension of this problem to the long-term, in which the resource mix can change. See, for example, Baumol (1979) and Kahn (1991). 


\section{Conclusions}

This study focused on methods of incorporating wind power into production-cost models. Within the LDC model framework, it appears that differences between methods may not be significant when the full year of wind data is used, although the results are clearly sensitive to wind data sample selection. Furthermore, from the aggregate perspective of total production-cost, it does not appear that the chronological framework differs significantly from the LDC approach, even though the chronological commitment appears to be more realistic and more accurate. However, it is obvious that chronological models provide the capability of answering important questions about wind resources that are difficult or impossible to address with LDC models. Given the recent dramatic increases in computing power, it is likely that the chronological models will (or already have) overcome their chief disadvantage of significant performance penalties so that utilities can achieve greater accuracy in production-cost modeling.

In the meantime, however, what can be expected from these two types of models? If the results of this study can be generalized, then we can make a few observations. First, LDC and chronological models appear to provide similar measurements of the value of wind generation to the utility. Second, certain types of questions relating to wind generation are beyond the scope of the LDC model because of the model's lack of detailed time resolution. However, this does not appear to significantly compromise the accuracy of the results that can be obtained from the LDC model.

The value of wind power to a utility depends on the marginal generating unit(s) displaced. This marginal cost is sensitive to several factors, most importantly, its definition. Because the production-cost model calculates expected output from the various generators, the actual generating mix will differ depending on which unit(s) is (are) on forced outage, thereby changing the marginal cost. Furthermore, marginal cost is heavily influenced by the load level; therefore, the value of a wind plant is sensitive to the load level used in the production simulation.

Modeling methods for intermittent resources in both chronological and LDC algorithms are still in need of some improvement. Although the load-modification method is probably the superior method because it preserves the time-varying capability of wind, neither the LDC nor the chronological modeling framework allows for both simple specifications of this time-varying feature and the uncertainty associated with intermittent generation. A possible caveat to this statement is that a promising method that was not investigated here, the branching technique in $\mathrm{P}+$, may provide this capability. Future work should address this issue, expand on the probabilistic supply-side approach with both LDC and chronological models, and explore the use of Monte Carlo and related methods to capture the variance that is so important to quantify. 


\section{BIBLIOGRAPHY}

Baumol, W. (1979), Economic Theory and Operations Analysis. Prentice Hall: Englewood Cliffs, New Jersey.

Billinton, R, and F. Gbeddy (1993), "Effects of Non-Utility Generators on Composite System Adequacy Evaluation." IEEE Transactions on Power Systems, Vol 8, No. 3.

Billinton, R, A. Jain, and C. MacGowan (1974), "Effect of Partial Outage Representation in Generation System Planning Studies." IEEE Transactions on Power Apparatus and Systems, Vol. PAS-9.3, No. 5.

Brothers, C., and J. teRaa (1993), "Assessing the Potential Capacity Credit of a Wind Farm in Prince Edward Island." Wind Engineering, Vol 17, No. 5.

Bryukhan, F., and R Diab (1993), "A Wind Power Simulation Model for a System of Compound Wind Farms." Wind Engineering, Vol 17, No. 1.

Caramanis, M., R Tabors, and K. Nochur (1982), "The Introduction of Non-dispatchable Technologies as Decision Variables in Long-tenn Generation-expansion Models." IEEE Transactions on Power Apparatus and Systems, Vol PAS-101, No. 8.

Chan, S., D. Powell, M Yoshimura, and D. Curtice (1983), "Operations Requirements of Utilities With Wind Power Generation." IEEE Transactions on Power Apparatus and Systems. Vol PAS-102, No. 9.

Clark, J. M. (1923), Studies in the Economics of Overhead Costs. University of Chicago Press: Chicago, Illinois.

Electric Power Research Institute (EPRI) (1982), Electric Generation-expansion Analysis System, Volume 1: Solution Techniques, Computing Methods, and Results. Palo Alto, California.

Environmental Defense Fund (1992), Elfin Algorithms Guide, Version 1.92. Oakland, California.

Flaim, T. and S. Hock (1984), Wind Energy Systems for Electric Utilities: A Synthesis of Value Studies. Solar Energy Research Institute, Golden, Colorado.

Grubb, M. (1991), "Value of Variable Sources on Power Systems." IEE Proceedings-C, Vol 138, No. 2.

Grubb, M. (1988), "The Economic Value of Wind Energy at High Power System Penetrations: An Analysis of Models, Sensitivities and Assumptions." Wind Engineering, Vol 12, No. 1.

Kahn, E. (1979), "The Reliability of Distributed Wind Generators," Electric Power Systems Research.

Kahn, E. (1991), Electric Utility Planning \& Regulation. The American Council for an Energy-efficient Economy, Washington, DC.

Marnay, C., and T. Strauss (1989), Chronological Model Comparison. California Public Utility Commission. 
Marnay, C., and T. Strauss (1990), Variance Reduction in Monte Carlo Chronological Production-cost Modeling. California Public Utilities Commission.

Milligan, M., and A. Miller (1993), "The Value of Windpower: An Investigation Using a Qualified Productioncost Model." Windpower '93 Proceedings; July 12-16, 1993; San Francisco, California. Washington, DC: American Wind Energy Association; pp. 74-81.

Milligan, M., A. Miller, and F. Chapman (1995), "Estimating the Economic Value of Wind Forecasting to Utilities." Windpower '95 Proceedings; March 27-30, 1995; Washington, DC. Washington, DC: American Wind Energy Association.

Rau, N., P. Toy, and K. Schenk (1980), "Expected Energy Production-costs by the Method of Moments." IEEE Transactions on Power Apparatus and Systems. Vol. PAS-99, No. 5.

Sandusky, W., J. Buck, D. Renné, D. Hadley, O Abbey, S. Bradymire, J. Gregory (1983), Candidate Wind Turbine Generator Site Cumulative Meteorological Data Summary and Data for January 1982 Through September 1982. Pacific Northwest Laboratory, Richland, Washington. PNL-4663. 


\section{Appendix: Selected Results for Utility U2}

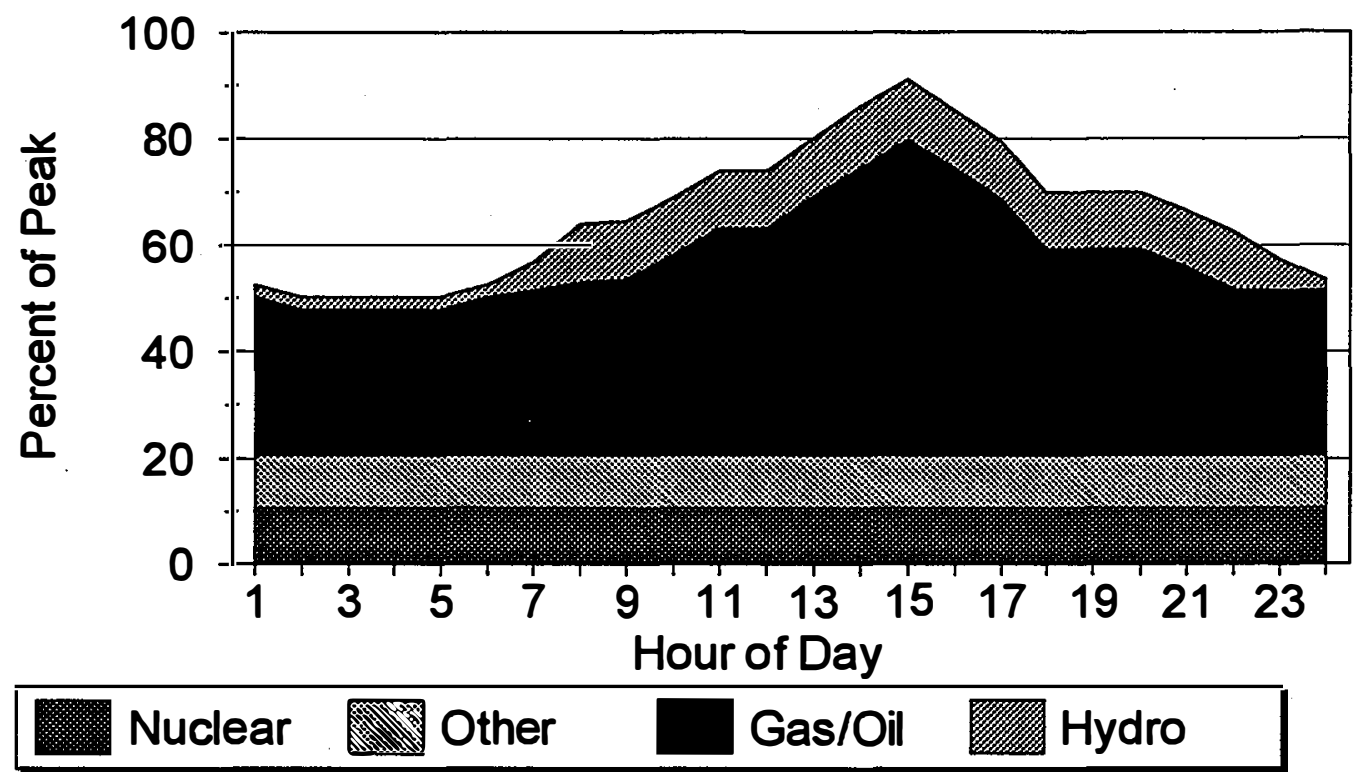

Figure 25. $P+$ peak day simulation for utility $U 2$, no wind

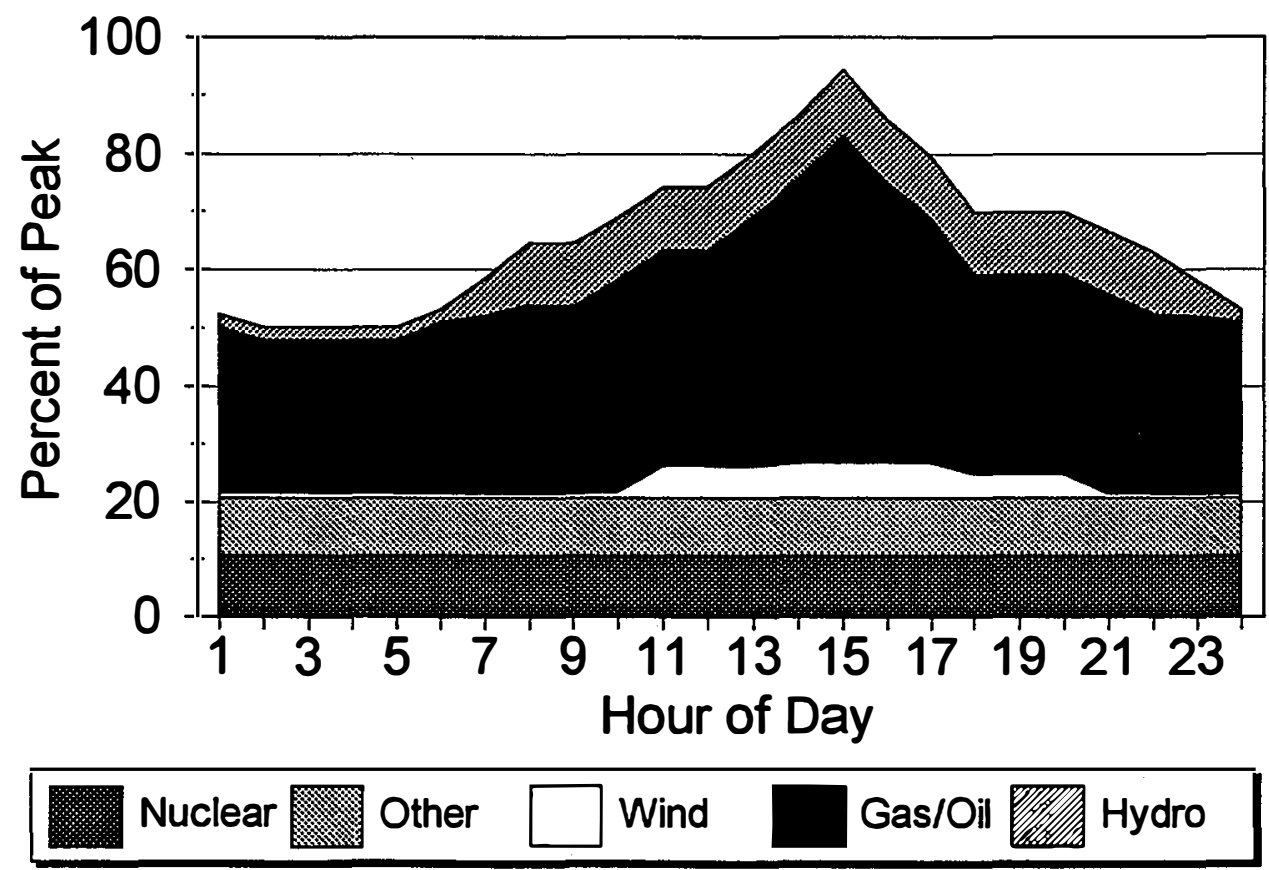

Figure 26. P+ peak day simulation for utility U2, High Plains wind A-1 


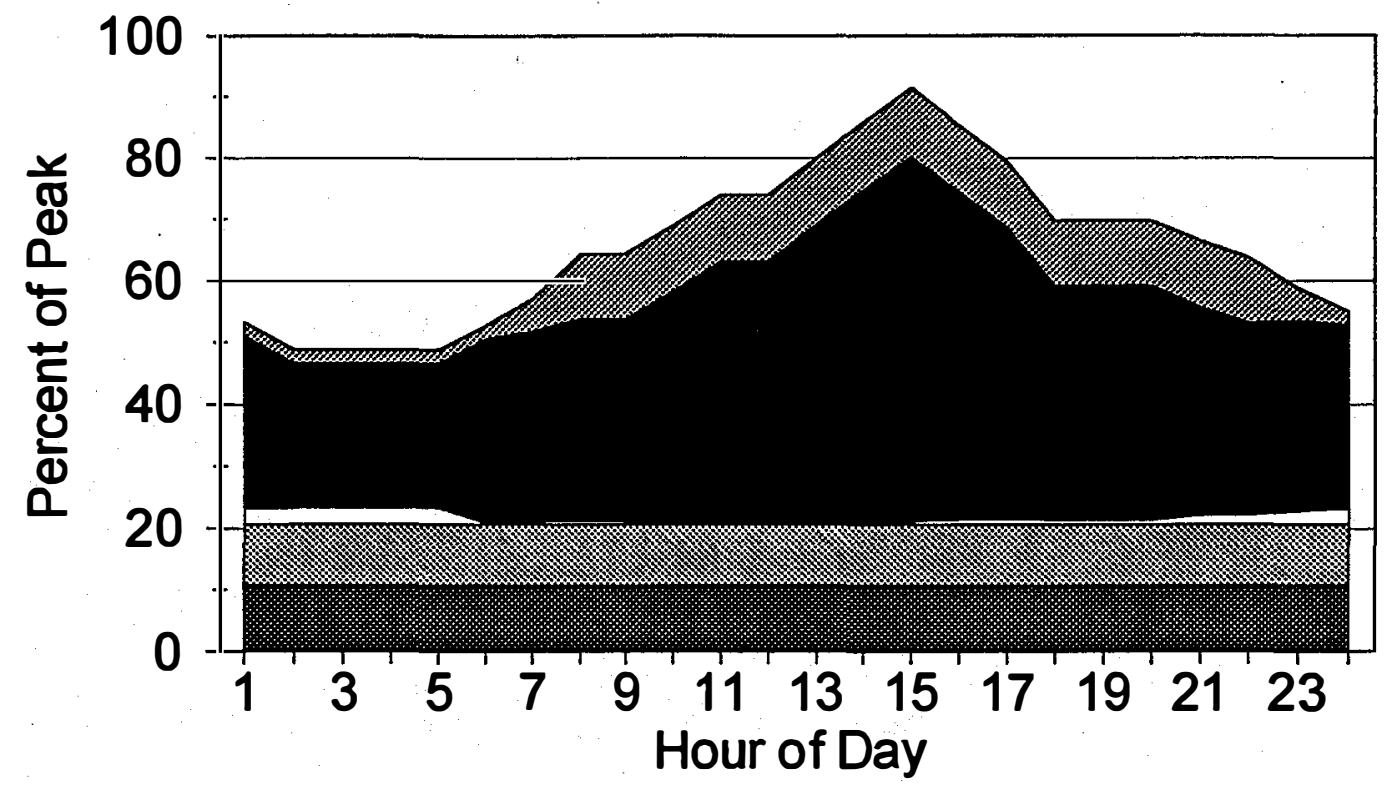

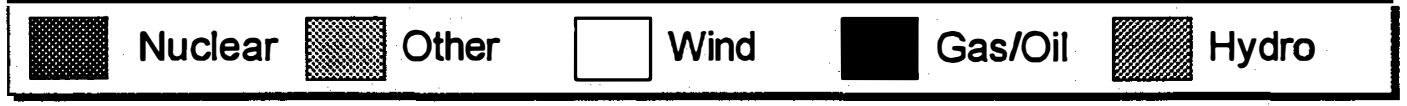

Figure 27. $P+$ peak day simulation for utility U2, West Coast wind

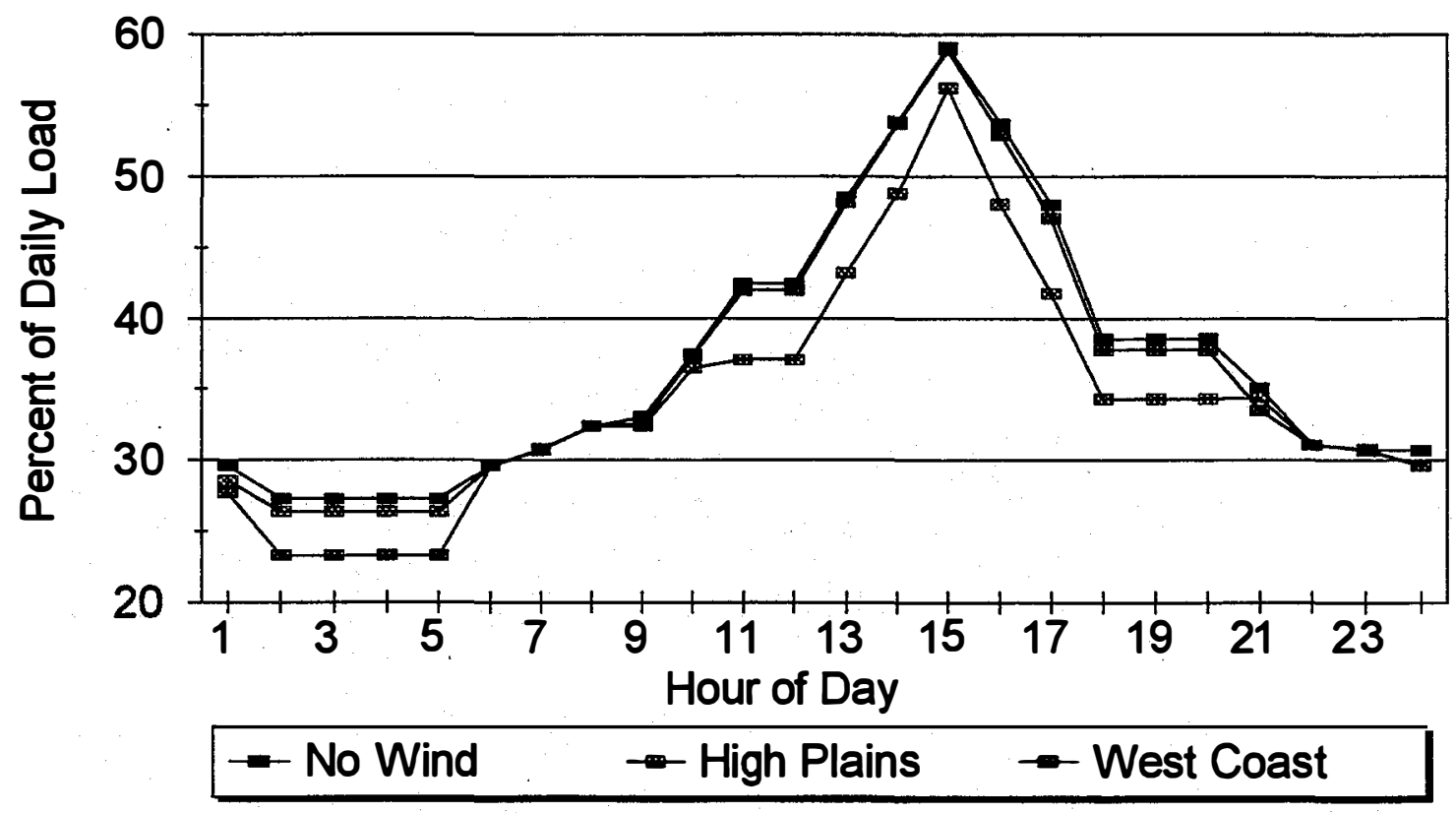

Figure 28. Utility $\mathbf{U} 2$ gas and oil comparison of peak day 


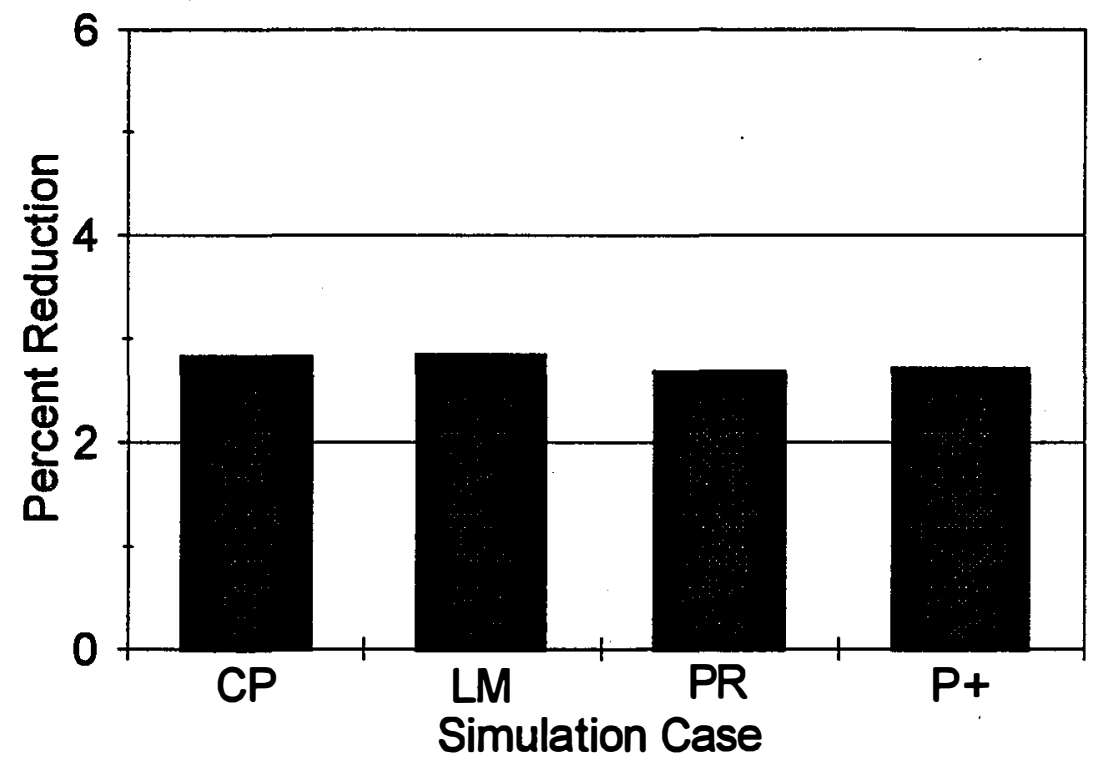

Figure 29. Cost reduction from base case, High Plains wind, utility U2

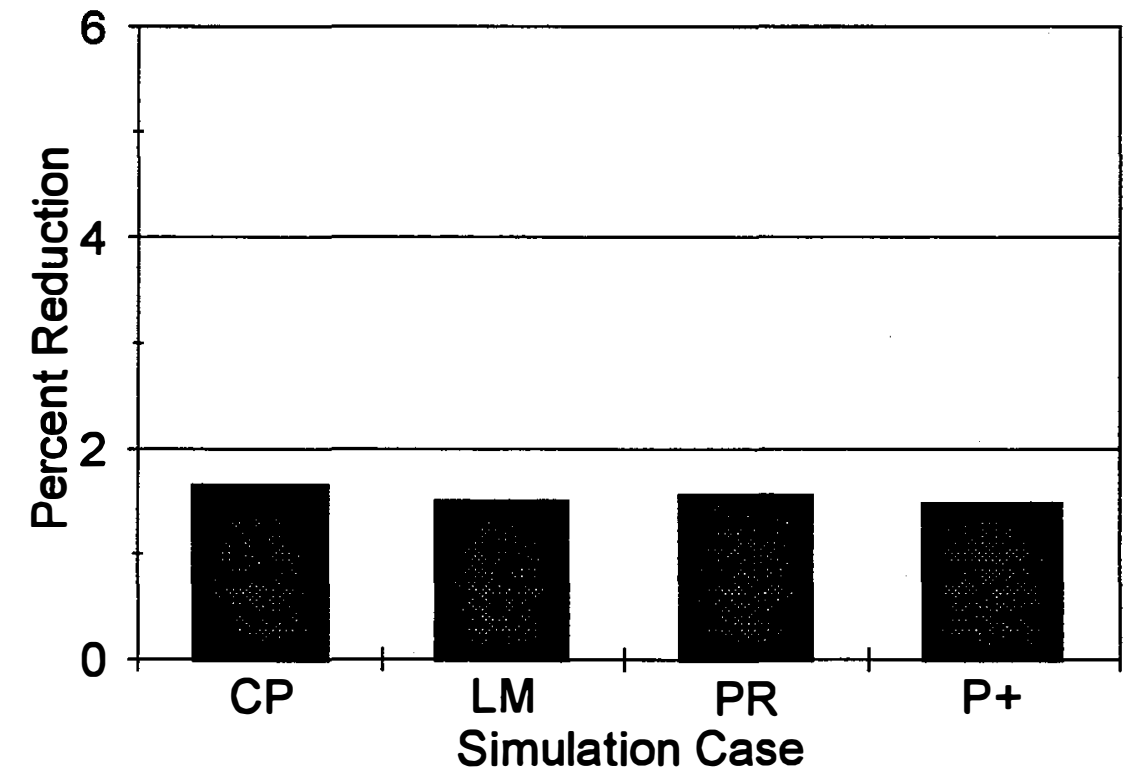

Figure 30. Cost reduction from base case, West Coast wind, utility U2 


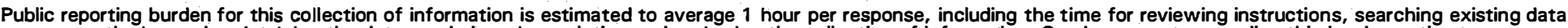

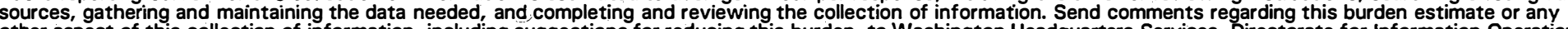

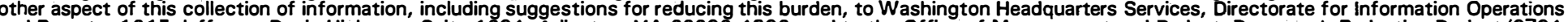

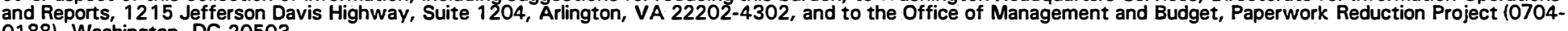
0188), Washington, DC 20503.

\begin{tabular}{|l|l|l|}
\hline 1. & $\begin{array}{c}\text { 2. REPORT DATE } \\
\text { April } 1996\end{array}$ & $\begin{array}{l}\text { 3. REPORT TYPE AND DATES COVERED } \\
\text { Technical Report }\end{array}$ \\
\hline
\end{tabular}

4. TITLE AND SUBTITLE Alternative Wind Power Modeling Methods Using Chronological and Load Duration Curve Production Cost Models

6. AUTHOR(S)

Michael R. Milligan

7. PERFORMING ORGANIZATION NAME(S) AND ADDRESS(ES)

National Renewable Energy Laboratory

1617 Cole Blvd.

Golden, CO 80401-3393

9. SPONSORING/MONITORING AGENCY NAME(S) AND ADDRESS(ES)

National Renewable Energy Laboratory

1617 Cole Blvd.

Golden, CO 80401-3393

5. FUNDING NUMBERS

C:

TA: WE617010

8. PERFORMING ORGANIZATION REPORT NUMBER

DE96007864

11. SUPPLEMENTARY NOTES

12a. DISTRIBUTION/AVAILABILITY STATEMENT

National Technical Information Service

U.S. Department of Commerce

5285 Port Royal Road

Springfield, VA 22161

13. ABSTRACT (Maximum 200 words)

As an intermittent resource, capturing the temporal variation in windpower is an important issue if the context of utility production cost modeling. Many of the production cost models use a method that creates a cumulative probability distribution that is outside the time domain. The purpose of this report is to examine two production cost models that represent the two major model types: chronological and load duration curve models. This report is part of the ongoing research undertaken by the Wind Technology Division of the National Renewable Energy Laboratory in utility modeling and wind system integration.

The author would like to gratefully acknowledge the encouragement and support of Jack Cadogan of the U.S. Department of Energy and Al Miller of Problem Solvers International. Francis Chapman at the Environmental Defense Fund, and Chok Pang and Granger Tam at the $\mathrm{P}+$ Corporation provided a wealth of modeling assistance.

14. SUBJECT TERMS wind energy; utility integration

15. NUMBER OF PAGES

16. PRICE CODE

17. SECURITY CLASSIFICATION OF REPORT

Unclassified

NSN 7540-01-280-5500
18. SECURITY CLASSIFICATION OF THIS PAGE Unclassified
19. SECURITY CLASSIFICATION OF ABSTRACT Unclassified
20. LIMITATION OF ABSTRACT

UL

Standard Form 298 (Rev. 2-89) Prescribed by ANSI Std. 239-1 